\title{
Origins of 1/f-like tissue oxygenation fluctuations in the murine cortex
}

Qingguang Zhang ${ }^{1, *}$, Kyle W. Gheres ${ }^{2}$ and Patrick J. Drew ${ }^{1,3,4 \ddagger}$

${ }^{1}$ Department of Engineering Science and Mechanics, The Pennsylvania State University, University Park, PA, USA

${ }^{2}$ Graduate Program in Molecular Cellular and Integrative Biosciences, The Pennsylvania State University, University Park, PA, USA

${ }^{3}$ Department of Neurosurgery, The Pennsylvania State University, University Park, PA, USA

${ }^{4}$ Department of Biomedical Engineering, The Pennsylvania State University, University Park, PA, USA

¥Correspondence to: (lead contact)

Patrick J. Drew

Department of Engineering Science \& Mechanics, Department of Neurosurgery, and Department of Biomedical Engineering, The Pennsylvania State University

W-317 Millennium Science Complex, University Park, PA 16802

Tel: (814) 863-1473

Email: pjd17@psu.edu

\section{*Correspondence to:}

Qingguang Zhang

Department of Engineering Science and Mechanics, The Pennsylvania State University

W-326 Millennium Science Complex, University Park, PA 16802

Email: qxz14@psu.edu

Running title: Vascular origin of 1/f-like tissue oxygenation fluctuations

Keywords: tissue oxygen, laminar electrophysiology, power spectrum, 1/f

\section{Metrics:}

Abstract: 155 words

Main text: 5256 words

Figures: 7

Supplementary figures: 7

References: 168 


\section{Abstract}

2 The concentration of oxygen in the brain spontaneously fluctuates, and the power distribution in 3 these fluctuations has 1/f-like dynamics. Though these oscillations have been interpreted as being 4 driven by neural activity, the origins of these 1/f-like oscillations is not well understood. Here, to 5 gain insight of the origin of the 1/f-like oxygen fluctuations, we investigated the dynamics of tissue 6 oxygenation and neural activity in awake behaving mice. We found that oxygen signal recorded 7 from the cortex of mice had 1/f-like spectra. However, band-limited power in the local field 8 potential, did not show corresponding 1/f-like fluctuations. When local neural activity was 9 suppressed, the 1/f-like fluctuations in oxygen concentration persisted. Two-photon 10 measurements of erythrocyte spacing fluctuations ('stalls') and mathematical modelling show that 11 stochastic fluctuations in erythrocyte flow and stalling could underlie 1/f-like dynamics in 12 oxygenation. These results show discrete nature of erythrocytes and their irregular flow, rather 13 than neural activity, could drive 1/f-like fluctuations in tissue oxygenation. 


\section{Introduction}

Fluctuations in oxygen tension are ubiquitous throughout the body, and are found in muscle tissue and tumors [1], in the retina [2, 3], in the carotid artery [4], and in the cortex [5-12]. Despite their ubiquity, relatively little is understood about the origin of these oxygen fluctuations. While some of these fluctuations are driven by fluctuations in respiration, such as the breathing rate and intensity [4, 13-20], fluctuations in oxygen concentration are present covering a wide range of frequency, not just at the respiration frequency, with most of the power concentrated at lower (< $0.1 \mathrm{~Hz}$ ) frequencies [1, 2, 5, 7-9]. The power spectrum of oxygen concentrations in many tissues show a "1/f-like" behavior, that is, the power at any given frequency $f$ is proportional to $1 / f^{\beta}$, where the exponent $\beta$ is usually between 1 and 2 [8]. We refer to these oscillations as being $1 / f-$ like because they are only characterized within a limited frequency region $(\geq 0.01 \mathrm{~Hz}$ and $\leq 1 \mathrm{~Hz})$. While many biological processes have been shown to exhibit $1 / f$-like dynamics, a process can only be said to be $1 / f$ if there is data over at least two orders of magnitude in both the abscissa and ordinate [21], a criterion that only a few studies meet [8]. In contrast, white noise has a constant power across frequencies, which when fitted with a power law gives a $\beta$ close to 0 (Figure 1a). In both cases, there can be "extra" spectral power concentrated in a single band, leading to a "bump" in the spectrum (Figure 1b). Measurements of tissue oxygenation in primates show a clear, statistically robust $1 /$ f-like power spectra, with an additional peak near $0.1 \mathrm{~Hz}$ [8].

In the brain, tissue oxygenation is determined by the balance between the oxygen supplied by the blood and the oxygen consumed by mitochondria. Both of these processes could contribute to fluctuations in oxygenation. In the brain, increases in neural activity are usually accompanied by vasodilation and increased blood flow/volume that leads to increases in oxygenation [22]. The resulting change in oxygenation will involve an interplay of factors, with the increase in blood flow usually, but not always, driving an oxygen increase [20]. The linkage of oxygenation to neural activity is widely used to infer neural activity non-invasively using BOLD fMRI [23], however, there are many examples of neural and vascular signals departing from this relationship [24-29]. Converging evidence from a large body of studies in both rodents and primates have shown that power in the gamma band (nominally $40-100 \mathrm{~Hz}$ ) of the local field potential (LFP) is most closely related to the vasodilation that leads to increased blood volume and flow [30-36]. Spiking activity has similar correlations to blood volume as gamma-band LFP power [30, 37, 38], while the correlations for other bands of the LFP are much lower [30, 31, 34].

There have been speculations that the ultra-slow $(<1 \mathrm{~Hz})$ electrical signals are the neural correlate of brain hemodynamics [39-41], but frequencies below $1 \mathrm{~Hz}$ in the LFPs are of a non- 
neuronal origin [36]. Because the electrical potential of the blood is negative relative to that of the cerebral spinal fluid [42, 43], changes in the blood volume in the brain will generate ultra-slow potentials. The dilation of arterioles (occurs over seconds) and veins (occurs over tens of seconds) in awake animals' brain [44-46] will generate changes $(<1 \mathrm{~Hz})$ in the LFP [47-50]. The nonneuronal origin of $<1 \mathrm{~Hz}$ electrical signals have been shown with manipulations that dilate or constrict blood vessels independent of changes in neural activity, such as $\mathrm{CO}_{2}$ inhalation [48-51], head-tilt and Valsalva maneuver [47]. Additionally, most amplifiers have circuitry setup to reject these very low frequencies [52], so unless the recording setup is specifically designed to measure at $\mathrm{DC}$ frequencies, signals $<1 \mathrm{~Hz}$ are not of a physiological origin.

Collectively, the neural correlate of vasodilation is increases in gamma-band power in the LFP. Though there are many studies investigating the relationship between neural activity and vasodilation, there is a paucity of studies looking simultaneously measuring neural activity and oxygen changes simultaneously [53-56], with only a handful looking in awake animals [8, 20,57]. Whether 1/f-like dynamics in brain oxygenation are driven by neural activity bears on the interpretation of hemodynamic imaging. Several fMRI studies have suggested that $1 / f-l i k e$ dynamics exist in human BOLD signals [58-61], and the 1/f-like fluctuations in brain hemodynamics have been interpreted as being driven by $1 / f-$ like fluctuations in neural activity [62, 63]. However, recordings of the LFP in both humans [64] and non-human primates [65] do not seem to show $1 / f$ dynamics in band-limited power.

As 1/f-like oxygen fluctuations are found in other tissue [1, 2], their origin may not be neural, and could come from vascular process. Blood flow and arterial diameter show fluctuations in a similar frequency range as oxygen fluctuations [3]. Additionally, as oxygen is carried by red blood cells (RBCs), fluctuations in the flux of RBCs can drive erythrocyte-associated transients (EATs) in oxygen in the tissue [66-82], and fluctuations in flux of these changes in local oxygenation in the cortex [83-86]. Stalls, brief stoppages in blood flow through capillaries happen sporadically and continuously in the cortex due to transient blockage of blood flow by leukocytes [87-92], which are known to greatly increase vascular resistance [93]. These blockages likely drive changes in tissue oxygenation [94] and increased frequency of these stalls has been linked to neurodegenerative disorders [87, 88, 94].

To understand the relationship between neural activity and 1/f-like oxygen tension oscillations in the brain, we used oxygen polarography to directly measure brain tissue oxygenation in different cortical regions and layers in awake mice. We find that in un-anesthetized, 
head-fixed mice: (1) cortical oxygenation showed 1/f-like power spectra that are similar across cortical regions and layers; (2) the band-limited power of LFP activity did not show 1/f-like power spectra; (3) there was significant coherence and correlation between neural activity and tissue oxygenation, but both were small; (4) silencing neural activity did not stop 1/f-like fluctuations in brain oxygenation; (5) simulations of erythrocyte flow taking into account the statistics of erythrocyte spacing show that the irregular nature of erythrocyte spacing can generate $1 / f-$ like dynamics in tissue oxygenation. Our results suggest that the driver of $1 / \mathrm{f}-$ like oxygenation fluctuations is non-neuronal in origin, and could be due to fluctuations in red blood cell flux.

\section{Results}

We measured tissue oxygenation signals and neural activity from the somatosensory and frontal cortices of awake behaving mice head-fixed on a spherical treadmill [20, 24, 30, 95]. We recorded laminar neural activity with linear multisite probes in 6 mice, laminar oxygenation using polarographic electrodes in 37 mice, and simultaneous neural activity, respiration and oxygen measurements in 9 mice. Additional 5 mice were used to measure RBCs spacing in capillaries using two-photon laser scanning microscopy (2PLSM). We reported results for rest period which only includes data from periods of time when the animal was not locomoting, or for all data, which includes periods of locomotion and rest. We did this because un-anaesthetized mice engage in spontaneous movement frequently, and these spontaneous movements are large drivers of neural activity and hemodynamic signals [30, 36, 96-98]. Specifically, cutaneous sensation during locomotion drives large increases in neural activity in the $\mathrm{FL} / \mathrm{HL}$ region $[20,24,99,100]$. The increase in neural activity drives localized increases in blood flow, which is not due to systemic factors [20,101]. Neural and oxygen measurements were made in the frontal cortex (FC) and in the forelimb/hindlimb region of the somatosensory cortex (FL/HL, identified by cytochrome oxidase staining [102]). All power spectra and frequency domain analyses were done using multitaper techniques [103], which minimize spectral leakage, using the Chronux toolbox (http://chronux.org/). Portions of this dataset have been published previously [20].

Brain oxygenation shows 1/f-like power spectrum with a band-limited component. We first asked if tissue oxygen concentrations $\left(\mathrm{PtO}_{2}\right)$ in the cortex of awake mice showed 1/f-like power spectra, as has been observed in the cortex of non-human primates [8]. We collected tissue oxygenation in multiple sites in 37 awake behaving mice (Figure 2a). The average duration of recording at each site was $37.0 \pm 11.6$ minutes. Examination of the resting $\mathrm{PtO}_{2}$ trace reveals that oxygen levels show slow fluctuations on the time scale of seconds or longer (Figure $2 \mathrm{~b}$ ). The power spectra of tissue oxygen signals, when plotted on a log-log axes, was linear, with a band 
112 limited component (in the range of 0.1-0.3 Hz) (Figure 2c), as seen in non-human primates [8].

113 The band-limited oscillations cover the frequency band in which spontaneous arterial oscillations

114 are seen in vivo when neural activity is blocked [30] and ex vivo in cannulated arteries [104-107].

115 As a control for any non-physiological sources of this signal [108], we measured $\mathrm{PtO}_{2}$ in a dead

116 mouse. The power spectrum of $\mathrm{PtO}_{2}$ in the dead mouse was essentially flat (Figure 2c),

117 characteristic of white noise (Figure 1b), and was several orders of magnitude smaller at all

118 frequencies, ruling out a non-physiological origin of these fluctuations.

We then qualified the nature of the power spectrum of oxygen fluctuations by fitting it with a power law distribution in the $0.01-1 \mathrm{~Hz}$ frequency range. To estimate the power-law exponent, we fitted the oxygen power spectrum using a linear regression (see Methods), to allow comparisons to previous studies [8], though there are caveats to this approach [109]. Averaged across all animals $(n=37)$, the power law exponent during rest was $1.42 \pm 0.21$, comparable to what have been observed in un-anaesthetized non-human primates (1.74) using oxygen-sensitive microelectrodes [8], but somewhat larger than those observed in human BOLD studies [58]. We then asked if the exponent of the fit to the power spectrum differed across cortical layers, since there are laminar differences in vascular, mitochondrial, and cellular density [110-112], which could affect the oxygen dynamics $[85,86]$. No significant differences were observed in different cortical depths at rest $(1.36 \pm 0.41$ at $100 \mu \mathrm{m}, 1.39 \pm 0.34$ at $300 \mu \mathrm{m}, 1.40 \pm 0.31$ at $500 \mu \mathrm{m}, 1.53$ \pm 0.33 at $800 \mu \mathrm{m}, \mathrm{n}=37$ mice, Figure 2f, Kruskal-Wallis test, $\left.\chi^{2}(3,146)=5.79, p=0.1223\right)$. We next asked if the 1/f-like dynamics of tissue oxygenation differed between FC and FL/HL, as different power-law exponent has been observed in different brain networks [58]. We did not observe a significant difference between the fitted exponents for FC ( $n=14$ mice, $1.41 \pm 0.13$, average across all cortical depths for each animal) and those of the FL/HL ( $n=23$ mice, $1.42 \pm$ 0.25 , average across all cortical depths for each animal, Wilcoxon rank sum test, $p=0.4810$ ). We then asked if the power law fit was affected by behavior, so we fitted the power spectrum of the whole dataset including both rest and locomotion data. Including all the data increased overall power, with most of the power increase occurred at lower frequency (Supplementary Figure 1). Including the locomotion periods increased the power law exponent $(n=37$ mice, rest: $1.42 \pm$ 0.21 , periods including both rest and locomotion: $1.81 \pm 0.14$, Figure $2 \mathrm{f}$, Wilcoxon signed rank test, $\mathrm{p}<0.0001)$.

These results show that, just as in primates [8], there are 1/f-like dynamics in the oxygen 143 levels in the cortex of mice. There was also a band-limited component, albeit at a slightly higher 144 frequency than that found in primates [8], close to the vasomotion frequency [30]. 


\section{Fluctuations in band-limited power of the LFPs do not show $1 / f$-like dynamics. To determine} whether neural activity exhibited similar dynamics to oxygen signals, we recorded LFPs (1-100 $\mathrm{Hz}$ ) and multi-unit activity (MUA, 300-3000 Hz) from 16-channel laminar electrodes placed in the FC ( $n=4$ sites) and FL/HL ( $n=6$ sites) during wakeful rest and locomotion in a separate group of mice ( $n=6$ mice, Figure 3a). Recording from one site from FC was excluded from this analysis as there was not enough resting data (see Methods). Broadband LFPs showed 1/f-like power spectra above $5 \mathrm{~Hz}$, but not below, and MUA activity have a relatively smaller slope (Supplementary Figure 2). The most relevant aspect of the LFP for the oxygen signal is the band-limited power (BLP, Figure $3 b$ and $c$ ), which is a measure of envelope amplitude changes of LFP oscillations at specific frequency bands. Previous studies have shown that BLP in the gamma-band $(40-100 \mathrm{~Hz})$ are best correlated with the time course of vessel dilation and oxygen changes $[20,25,30-32,34,38,113]$, we next calculated the power of gamma-band LFP oscillations (see Methods, Figure 3d) and estimated the power law fitting exponent. In contrast to the broad-band LFPs, a flat power spectrum was observed in the gamma-band BLP in the frequency range below $1 \mathrm{~Hz}$ at rest $(-0.15 \pm 0.14$ at $100 \mu \mathrm{m},-0.03 \pm 0.18$ at $300 \mu \mathrm{m},-0.08 \pm 0.16$ at $500 \mu \mathrm{m}, 0.11 \pm 0.96$ at $800 \mu \mathrm{m}$, Figure 3d left, one-way ANOVA, $F(3,35)=0.42, p=0.74)$, which shows a characteristic of white noise (Figure 1b). Fitting all the data, including both rest and locomotion periods, significantly increased the power law exponent (rest: $-0.04 \pm 0.49$, run: $0.38 \pm 0.55$, Wilcoxon rank sum test, $p<0.0001)$, and showed no laminar difference $(0.19 \pm 0.37$ at $100 \mu \mathrm{m}, 0.31 \pm 0.35$ at $300 \mu \mathrm{m}, 0.35 \pm 0.35$ at $500 \mu \mathrm{m}, 0.69 \pm 0.89$ at $800 \mu \mathrm{m}$, Kruskal-Wallis test, $\chi^{2}(3,35)=2.44, p=0.4856$, Figure $3 \mathrm{~d}$ right). The power spectra of the sub-alpha $(1-8 \mathrm{~Hz})$ BLP and beta $(10-30 \mathrm{~Hz})$ BLP revealed similar results, characterizing white noise (Supplementary Figure 3). This shows that the power spectra of BLP fluctuations of LFPs in mice do not have 1/f-like dynamics, consistent with recordings from non-human primates and humans $[64,65,114]$.

Weak correlations between tissue oxygenation dynamics and electrophysiology. The large mismatch between the power-law fit exponents of the power spectrums for band-limited power of LFPs and oxygen fluctuations suggest that their relationship is weak. We then asked how correlated/coherent our oxygen signals were with simultaneously recorded neural activity at rest. To answer this question, we simultaneously measured tissue oxygenation, respiration and LFP activity in 9 animals (see Methods). To differentiate the frequency dependency of the correlation, we calculated the magnitude-squared coherence between oxygen and band-limited power of LFP, as well as the coherence between oxygen and respiratory rate. The magnitude-squared 
178 coherence at a given frequency is equivalent to the $\mathrm{R}^{2}$ between the two signals bandpass filtered 179 at the frequency [36]. A weak but statistically significant level of coherence between BLP of LFP 180 and oxygen was observed between $0.01-1 \mathrm{~Hz}$, with larger coherence at the lower frequencies 181 (Figure 4a-c). However, the magnitude of this squared coherence (which will report the fraction 182 of variance in the signal at that frequency) was low, less than 0.2 , implying $>80 \%$ of the observed 183 variance was not (linearly) predicted by neural activity. This low value should be viewed in light of 184 previous work comparing the correlations of the BOLD signal with simultaneously measured 185 electrophysiological signals in awake primates. These studies found correlation coefficients (R) 186 between gamma-band LFP power and the hemodynamic signals were in the range of 0.3-0.4 [34, $187113,115]$. The amount of variance explained $\left(R^{2}\right)$ by neural activity can be obtained by squaring 188 the correlation coefficient, giving a value in the range of $10-20 \%$, meaning that $80-90 \%$ of the observed BOLD signal is uncorrelated with neural activity, similar to our results.

As another test of how well neural activity can predict changes in oxygenation, we calculated the oxygen hemodynamic response function (HRF, Figure 5b) by de-convolving 192 oxygen signals from gamma-band power fluctuations of LFP [20,30], using the first half of the 193 data from each site. We fit the deconvolved HRF with the sum of two gamma distribution functions 194 (see methods), which is standard in the field [25, 37, 116-119] to create a smoothed HRF. There 195 was a good agreement between the deconvolved and smoothed HRFs (goodness of fit: $0.73 \pm$ 1960.39 , median \pm interquartile range). As increases in gamma-band power will lead to vasodilation 197 and increases in oxygenation, we quantified the positive peak of the gamma distribution fitting. 198 The positive peak of the smoothed HRF (time to peak $=2.99 \pm 0.31 \mathrm{~s}$, mean $\pm \mathrm{SEM}, \mathrm{n}=9$ mice), 199 and the full-width at half maximum of the HRFs $(3.90 \pm 3.35 \mathrm{~s}$, median \pm interquartile range, $\mathrm{n}=$ 2009 mice) were comparable to the dynamics of those seen in previous measurements of cerebral oxygen dynamics $[120,121]$ and BOLD fMRI $[122,123]$.

We then tested how well the HRF to predict tissue oxygenation from neural data. We convolved the HRF with gamma-band power fluctuations using the second half of the data, to get 204 a simulated oxygen signal, which reflects the oxygen component predicted by neural activity 205 (Supplementary Figure 4). This model uses the same assumptions built into the analysis of 206 BOLD fMRI data, that the observed signal (oxygen concentration or BOLD) is a linear convolution 207 of the neural activity with an $\operatorname{HRF}[20,25,30,37,124]$. We then compared the power spectrum 208 between the observed versus the predicted oxygenation. We used data during periods including 209 both rest and locomotion. We found that the oxygen concentration predicted from the neural 210 activity only predicted a small amount of the variance $\left(R^{2}\right)$ of the signal $\left(R^{2}=0.04 \pm 0.06, n=9\right.$ 
211 mice). Furthermore, the power spectrum of the oxygen fluctuations predicted from the neural 212 activity did not show the same frequency dependence as the actual oxygen fluctuations (Figure

$2135 \mathrm{c}$ and $\mathrm{d}$, observed: $1.87 \pm 0.35$, predicted: $1.11 \pm 0.46$, paired t-test, $\mathrm{t}(8)=3.2520, \mathrm{p}=0.0117)$.

214 Note that the predicted power spectrum was $\sim 63 \%$ smaller than the actual power spectrum at

215 frequencies below $0.1 \mathrm{~Hz}$ (Figure 5c, paired t-test, $\mathrm{t}(8)=3.8348, \mathrm{p}=0.0050$ ), indicating that 216 putative non-neuronal components contribute more to the frequencies below $0.1 \mathrm{~Hz}$. These 217 results are consistent with the hypothesis that neural activity does not drive 1/f-like dynamics in 218 tissue oxygenation.

219 Impact of suppressing neural activity on tissue oxygenation 1/f-like dynamics. While we 220 found that the majority of the observed oxygen fluctuations could not be explained by neural 221 activity (Figure 4 and Figure 5), if the relationship between neural activity and oxygenation is not 222 captured by the HRF, such as the nonlinearity of brain hemodynamics [125], then some aspect 223 of neural activity might still explain the oxygen fluctuations. To test this possibility mechanistically, 224 we pharmacologically silenced neural activity in the cortex [20,30], which will also block increases 225 in blood flow mediated by these increases in neural activity [20, 30]. If the 1/f-like power spectrum 226 in oxygen concentration goes away when neural activity is silenced, this would suggest that the 227 fluctuations are due to neural activity and the subsequent vasodilation. If, however, the 1/f-like 228 power spectrum is still present, this would suggest that these oscillations have a non-neuronal 229 origin. To mechanistically understand whether the observed $1 / f-$ like properties of oxygen signals 230 is due to coherent neural activity fluctuations, we superfused the craniotomy with a cocktail of 231 CNQX/AP5/muscimol to suppress neural activity, and recorded tissue oxygenation and LFP 232 simultaneously (Figure 6a, Supplementary Figure 5). Application of CNQX/AP5/muscimol 233 significantly and substantially suppressed the gamma-band LFP power by $89 \pm 8 \%$ (Wilcoxon 234 signed-rank test, $p=0.0039$ ) and variance by $77 \pm 21 \%$ (paired t-test, $t(8)=5.0246, p=0.0010$ ), 235 but did not change the variance of the tissue oxygenation signal (Figure 6b and c, paired t-test, $236 \mathrm{t}(8)=0.7542, p=0.4723)$, which suggests that the magnitude of the fluctuations were not reduced 237 by silencing neural activity.

We then asked if the suppression of neural activity alters the $1 / \mathrm{f}$-like characteristics of the $239 \mathrm{PtO}_{2}$ power spectrum. If the oxygenation fluctuations are driven by neural activity, decreasing 240 neural activity should reduce the amplitude of the oxygen fluctuations. The power spectrum of 241 spontaneous oxygen fluctuations under aCSF had a power law exponent of $1.42 \pm 0.40$ ( $\mathrm{n}=8$ 242 mice) during rest. Application of CNQX/AP5/muscimol significantly increased the power-law 243 exponent to $2.06 \pm 0.33$ (paired t-test, $t(7)=5.3358, p=0.0011$, Figure $6 \mathrm{~d}$ and $\mathrm{e}$ ) during rest. A 
significant increase of power law exponent was also observed when using the entire dataset (aCSF: $1.89 \pm 0.37 ; \mathrm{CNQX/AP5/muscimol:} 2.16 \pm 0.25 ; \mathrm{n}=9$ mice, paired t-test, $\mathrm{t}(8)=2.6261, \mathrm{p}$

$246=0.0304$, Figure $6 \mathrm{~d}$ and e). Silencing neural activity did not affect the amplitude of oxygen 247 fluctuations below $0.1 \mathrm{~Hz}$ (aCSF: $5.24 \pm 4.18 \mathrm{mmHg} / \mathrm{Hz}$; CNQX/AP5/muscimol: $6.74 \pm 5.76$ $248 \mathrm{mmHg}^{2} / \mathrm{Hz}$; Wilcoxon signed-rank test, $\left.\mathrm{p}=0.5469\right)$, though there was a decrease in the amplitude 249 of oxygen fluctuations above $0.1 \mathrm{~Hz}$ during rest (aCSF: $0.49 \pm 0.26 \mathrm{mmHg} / \mathrm{Hz}$; 250 CNQX/AP5/muscimol: $0.29 \pm 0.27 \mathrm{mmHg}^{2} / \mathrm{Hz}$; Wilcoxon signed-rank test, $\left.p=0.0078\right)$. These 251 results reflect that the infra-slow $(<0.1 \mathrm{~Hz})$ oscillations in brain oxygenation are not predicted by 252 neural activity, which is consistent with the observation that these oscillations are primarily not 253 driven by neural activity (Figure 5c). Taken together, these results show that suppressing neural activity did not abolish 1/f-like oscillations in tissue oxygenation or decrease the amplitude of the oxygen fluctuations, suggesting that non-neuronal contributions are a major driver of these dynamics. Notably, suppressing neural activity does not change the 1/f-like dynamics in both broadband LFP and BLP fluctuations (Supplementary Figure 5).

Respiration is a major factor affects brain oxygenation [20], and fluctuations in respiration rate are known to drive substantial changes in BOLD fMRI signals $[13,15,19,126]$. If the respiration rate shows 1/f-like dynamics [127], this could account for the fluctuations in

261 oxygenation that we see in the tissue when neural activity was suppressed. We found no evidence

262 for 1/f-like dynamics in the respiration rate during rest (Supplementary Figure 6). Suppressing 263 neural activity significantly affected the mouse behavior (i.e., reduced the time mice spend 264 locomoting), but did not affect the respiration dynamics during rest ( $\mathrm{n}=8$ mice; fitted exponent for aCSF: $0.27 \pm 0.13$; CNQX/AP5/muscimol: $0.27 \pm 0.04$; Wilcoxon signed-rank test, $p=0.8785$ ). Including data during locomotion did not yield an exponent above 1 ( $\mathrm{n}=9$ mice; aCSF: $0.60 \pm$ 0.19; CNQX/AP5/muscimol: $0.46 \pm 0.21$; Wilcoxon signed-rank test, $p=0.1359$ ). The lack of $1 / f-$ like dynamics in respiration indicate that fluctuations in blood oxygenation due to the fluctuations in respiration are not the origin of the observed 1/f-like oxygen dynamics in the cortex.

270 Role of RBCs spacing variations in generating 1/f-like tissue oxygenation fluctuations. The 271 vast majority of oxygen in the blood is carried by RBCs, with the plasma carrying a small fraction 272 of the total oxygen [78, 83, 85, 86], which means heterogeneities in RBCs densities will cause 273 changes in local oxygen supply [67, 70, 72, 78, 83-86]. It has long been appreciated from 274 theoretical models that the tissue oxygenation can vary with the passage of a single RBC, creating an erythrocyte-associated transient (EAT) in tissue oxygenation [66-82]. Recent high-resolution measurements of oxygenation with phosphorescent dyes have confirmed the existence of these 
277 transients [67, 72, 83-86], but these measurements require aligning the signals to the passage of 278 the RBCs and would not be able to assay any slow oxygenation change that drive 1/f-like 279 dynamics. Notably, oxygen sensitive electrodes used in the present study lack the temporal 280 resolution to detect the EATs. As RBCs transit through the capillaries in single file flow, the tissue 281 oxygenation outside the capillary fluctuates with their density (Figure 7e). Interestingly, there are 282 infrequent "stalls" in RBCs flow in capillaries, caused by leukocytes transiently blocking flow [87, 283 88, 92, 128, 129]. During a stall, a large RBC spacing will result in a sudden drop of tissue 284 oxygenation within $\sim 15 \mu \mathrm{m}$ [110] of the capillary. As theoretical work has shown that pulsatile time 285 series generate 1/f-like spectra [130], we asked if the variations in RBCs density through single capillaries had 1/f-like dynamics.

To answer this question, we measured inter-RBCs spacing in capillaries using 2PLSM to perform line scans along individual capillaries [131]. The plasma is labeled with a fluorescent dye, and RBCs appear as dark streaks (Figure 7a), and the pattern of RBCs and plasma was thresholded and binarized to generate a train of point processes. A "stall" event was defined as an inter-RBC spacing of $>1 \mathrm{~s}$. We first quantified the nature of the power spectrum of RBCs arrival fluctuations during rest by fitting the power spectrum of the binarized data (0: plasma; 1 : $\mathrm{RBC}$ ) with a power law distribution in the $0.01-1 \mathrm{~Hz}$ frequency range. Binarization makes sense, as the oxygen levels will be high as an RBC passes by, and low when there is only plasma present. We observed 1/f-like dynamics of RBCs spacing, with the exponent range from 0.6 to 1.3 (0.98 \pm 0.23, 12 capillaries in 5 mice, Figure $7 \mathrm{~b}-\mathrm{d}$ ). Note that the occurrence of RBCs "stall" events did not significantly affect the fitted exponent (Figure $7 d$, two sample t-test, $p=0.2848 ; 0.88 \pm 0.15$, 4 capillaries with stall events; $1.03 \pm 0.25,8$ capillaries without stall events). The inter-RBC interval correlations show that RBCs tend to cluster together in time (Figure $7 \mathrm{~b}$ ). The rare occurrence of "stall" events in our data is consistent with previous work [92, 94, 128].

We then developed a simple computational model to determine how the delivery of oxygen by RBCs is affected by the statistics of RBC passages. Given the volume of tissue sampled by the electrode [132], and the spacing of capillaries [110], the oxygen signal at our electrode will be dominated by the nearest capillary. We generated a time series of RBCs spacing (see Methods) utilizing data from our 2PLSM observations and data from previous studies [92, 128], as well as the previously measured oxygen changes associated with RBC passage [83-86]. We only considered the tissue oxygenation transients caused by the RBCs spacing. The RBCs (with high $\mathrm{PO}_{2}$ ) and plasma gaps (with relatively low $\mathrm{PO}_{2}$ ) alternately passed through the capillary, and the EAT maybe visualized by considering a fixed measurement site on the capillary wall (Figure 7e). 
310 As the tissue response time is much slower compared to the RBC transit time (due to the low311 pass filtering nature of the oxygen diffusion dynamics), the oxygen delivery from capillaries

312 decays rapidly with distance at higher temporal frequencies. This means that the tissue

313 oxygenation will be a smoothed version of the EATs (Figure 7e). Based on our observation, we

314 created a RBC time series with a power spectrum with a fitted exponent 1. The RBCs were

315 considered as a point process, and the EATs surrounding each RBC were modelled using an

316 exponential decay (Figure 7e), based on the data measured using two-photon phosphorescent

317 imaging [83-86]. The tissue response time [73] was also considered when calculating the tissue

318 oxygen at different length from the capillary, as oxygen delivery from capillaries decays rapidly

319 with distance at high frequencies of pulsatile flow in the vessels (Figure 7e). We generated

320 simulations of oxygenation of comparable length of our data using polarographic electrodes ( $\sim 40$

321 minutes), and examined the power spectrum. Figure $7 f$ illustrated a representative RBC train we

322 modelled with $5 \%$ stall events and a power spectrum with a fitted exponent 1 . The generated data

323 has shown that RBC spacing fluctuations have long-range autocorrelations (Figure 7g), as seen

324 in the data. We assumed that oxygenation of each $\mathrm{RBC}\left(\mathrm{PO}_{2}=80 \mathrm{mmHg}\right)$ and oxygenation in

325 each plasma gap $\left(\mathrm{PO}_{2}\right.$ interRBC $=28 \mathrm{mmHg}$ ) were constant, giving a EAT magnitude of $52 \mathrm{mmHg}$,

326 consistent with measurements in awake animals [85, 86]. Altering the EAT magnitude did not

327 affect the slope (Supplementary Figure 7). The power spectrum of tissue oxygenation

328 fluctuations originated from RBCs heterogeneity had a slope 1.28 , and the simulations showed

329 very close agreement with the data (Figure $7 \mathrm{~h}$ ).

330 Taken together, our simulations show that variations of RBC spacing alone can generate

331 1/f-like oxygen fluctuations in the capillaries and surrounding tissue. This simple model points to

332 an intriguing possibility that the discrete nature of RBCs may play a more important role in 1/f-like

333 dynamics of oxygen supply. As the fluctuations of RBCs are largely attributed to non-neuronal

334 mechanisms [129, 133], suggesting a non-neuronal origin of 1/f-like oscillations in tissue

335 oxygenation.

336 Discussions

337 We found that oxygen dynamics in the mouse cortex show large, low frequency oscillations which 338 were absent in the band limited power of the LFP. These fluctuations were present in all cortical 339 layers and multiple regions both when the mouse was at rest and during behavior. These 340 fluctuations were weakly correlated with neural activity and persisted when neural activity was 341 pharmacologically suppressed. Simulations based on physiological measurements showed that 
the stochastic, correlated fluctuations in the number of red blood cells could account driving these dynamics.

A large vascular contribution to the $1 / f-$ like dynamics in tissue oxygen could potentially explain many disparate observations. It would explain why $1 / f$-like dynamics are seen in tissue oxygenations throughout the body [1, 5, 8, 9], why we see similar oxygen dynamics across layers and cortical regions (Figure 2) even though there are large differences in neural activity and vascular density across regions and layers [110-112]. Fluctuations in oxygenation generated by the stochastic passage of RBCs are 'noise' and could explain the low correlations and coherences between oxygen and neural activity observed both in our experiments and in BOLD fMRI measures [34, 113, 115].

Besides the RBC heterogeneity, there may be other contributors to oxygen dynamics. The tissue oxygenation is determined by an interplay of metabolism and supply. Fluctuations in the consumption of oxygen by mitochondria may also contribute to the $1 / f$-like dynamics both at the single cell level [134-137] and at the system level [138]. Moreover, measurements in awake and sleeping cats have shown that existence of spontaneous oscillating metabolic phenomenon in cortex that is not directly related to neural activity [139]. However, oxygen consumption by neurons in rat hippocampal slices is closely tied to neural activity [140] and oxygen levels in the slices lack the fluctuations seen in perfused tissue. This suggests that non-neural related metabolic activity is a potential contributor to the observed oxygen $1 / \mathrm{f}$-like dynamics.

In addition to stalls in flow caused by vessel occlusion by leukocytes [87, 88, 92, 94, 128 , 129], the very nature of the RBC-plasma suspension will drive low-frequency fluctuations in flow and RBC heterogeneity $[133,141]$. RBCs have different rheological properties than the plasma [142, 143], making the Newtonian descriptions of fluid flow that works for larger vessels inapplicable to the flow through capillaries. Because of the higher effective viscosity of RBC than the plasma, stochastic fluctuations in the number of RBC in a vessel changes the effective resistance of the vessel, which can lead to low frequency fluctuations in RBC flow [133, 141]. Besides these coagulation factors affecting capillary blood flow, the temporal and spatial capillary flow dynamics are also affected by the contractile dynamics of pericytes [144-146]. Though we modelled the RBC and oxygenation dynamics in one single capillary, the vasculature topology will introduce additional level of complexity, and affects how the RBCs are distributed within the network $[133,141]$ and subsequently affect oxygenation dynamics. 
Collectively, our results suggest that processes affect the location and frequency of stalling

374 events and RBC heterogeneity will greatly impact the levels of oxygen in the tissues. Besides the

375 aforementioned leukocytes caused "stall" events [87, 88, 92, 94, 128, 129], the temporal dynamics

376 of RBCs in the capillary may also reflect general features of the capillary network supply the same

377 brain region [133, 141]. It is also possible that the arterial blood pressure fluctuations [147], heart

378 beat dynamics [148], upstream vessel diameter oscillations [44], rheological properties of flowing

379 blood [142, 143] and anatomical structures of capillary [149], and the dilation of capillaries and 380 activity of pericytes[144, 146, 150, 151] contribute to the stochastic RBC dynamics. 
381 Acknowledgements: We thank Nanyin Zhang, Yuncong Ma for comments on this manuscript.

382 This work was supported by the National Institutes of Health grant R01NS078168 to P.J.D., and

383 the National Institutes of Health grant R01NS108407 "Understanding cellular architecture of the

384 neurovascular unit and its function in the whole mouse brain" to Dr. Yongsoo Kim (Department of

385 Neural and Behavior Sciences, College of Medicine, The Pennsylvania State University).

386 Author contributions: Q.Z. and P.J.D. designed the project. Q.Z. performed experiments using 387 polarographic oxygen electrodes, pharmacological manipulation, and two-photon laser scanning 388 microscopy. K.W.G. performed experiments measuring laminar electrophysiology. Q.Z. 389 performed all the data analysis and implemented the computational modelling. Q.Z. and P.J.D. 390 wrote the manuscript. P.J.D. supervised experiments, data analysis, and preparation of the 391 manuscript. 


\section{Materials and Methods}

393 Portions of the data used in this study have been published previously [20]. This study was performed in strict accordance with the recommendations in the Guide for the Care and Use of Laboratory Animals of the National Institutes of Health. All procedures were performed in accordance with protocols approved by the Institutional Animal Care and Use Committee (IACUC) of the Pennsylvania State University (protocol \#201042827).

Animals. A total of 47 C57BL/6J mice (3-8 months old, 25-35 g, Jackson Laboratory) were used. Recordings of laminar cortical tissue oxygenation were made from 37 mice [23 (13 male and 10 female) in the somatosensory cortex (FL/HL) and 14 (7 male and 7 female) in the frontal cortex (FC)] using Clark-type polarographic microelectrode. Simultaneous measurements of cortical tissue oxygenation using polarographic electrodes, respiration and local field potential were conducted in 9 mice [5 (4 male and 1 female) in FL/HL and 4 (2 male and 2 female) in FC]. Six of these mice were also used for laminar cortical tissue oxygenation measurements. Local field potential and spiking activity of different cortical layers were measured using laminar electrodes in a separate set of 7 male mice (4 in FC and 6 in FL/HL, 3 mice were measured in both $\mathrm{FL} / \mathrm{HL}$ and FC simultaneously). Two-photon laser scanning microscopy (2PLSM) imaging was conducted in 5 mice (12 capillaries, 3 male and 2 female, in FL/HL). Mice were given food and water ad libitum and maintained on 12-hour (7:00-19:00) light/dark cycles. All experiments were conducted during the light period of the cycle.

411 Surgery. All surgeries were performed under isoflurane anesthesia (in oxygen, 5\% for induction and $1.5-2 \%$ for maintenance). A custom-machined titanium head bolt was attached to the skull with cyanoacrylate glue (\#32002, Vibra-tite). The head bolt was positioned along the midline and just posterior to the lambda cranial suture. Two self-tapping 3/32" \#000 screws (J.I. Morris) were implanted into the skull contralateral to the measurement sites over the frontal lobe and parietal lobe. A stainless-steel wire (\#792800, A-M Systems) was wrapped around the screw implanted in the frontal bone for use as an electrical ground for cortical tissue oxygenation and neural recordings. For capillary blood flow velocity measurements using 2PLSM ( $n=5$ mice), a polished and reinforced thin-skull (PoRTS) window was made covering the right hemisphere as described previously [20, 24, 30, 45, 101, 152]. For simultaneous measurement of tissue oxygenation and

421 neural activity ( $n=9$ mice), we implanted two electrodes to measure LFP signals differentially.

422 Electrodes were made from Teflon-coated tungsten wire (\#795500, A-M Systems) with 1 mm

423 insulation striped around the tip. The electrodes were inserted into the cortex to a depth of 800 $424 \mu \mathrm{m}$ at $45^{\circ}$ angle along the rostral/caudal axis using a micromanipulator (MP-285, Sutter 
Instrument) through two small burr holes made in the skull. The two holes for the electrodes were made $\sim 1-1.5 \mathrm{~mm}$ apart to allow insertion of the oxygen probe between the two electrodes in following experiments. The holes were then sealed with cyanoacrylate glue. Following the surgery, mice were then returned to their home cage for recovery for at least one week, and then started habituation on experimental apparatus. Habituation sessions were performed 2-4 times per day over the course of one week, with the duration increasing from $5 \mathrm{~min}$ to $45 \mathrm{~min}$.

Physiological measurements. Data from all experiments, except experiments using 2PLSM, were collected using custom software written in LabVIEW (version 2014, National Instruments).

Behavioral measurement. The treadmill movements were used to quantify the locomotion events of the mouse. The animal was also monitored using a webcam (Microsoft LifeCam Cinema ${ }^{\circledR}$ ) as an additional behavioral measurement.

Cerebral tissue oxygenation measurement using polarographic electrode. On the day of measurement, the mouse was anesthetized with isoflurane $(5 \%$ for induction and $2 \%$ for maintenance) for a short surgical procedure ( 20 min). A small ( 100 x $100 \mu \mathrm{m})$ craniotomy was made over the frontal cortex ( 1.0 to $3.0 \mathrm{~mm}$ rostral and 1.0 to $2.5 \mathrm{~mm}$ lateral from bregma) or the forelimb/hindlimb representation in the somatosensory cortex $(0.5$ to $1.0 \mathrm{~mm}$ caudal and 1.0 to $2.5 \mathrm{~mm}$ lateral from bregma), and dura was carefully removed. The craniotomy was kept moist with warm artificial cerebrospinal fluid (aCSF) and porcine gelatin (Vetspon). The mouse was then moved to and head-fixed upon the spherical treadmill. Oxygen measurements started at least one hour after cessation of anesthesia to minimize the effects of anesthesia [85, 95, 153].

Cerebral tissue oxygenation was recorded with a Clark-type oxygen microelectrode (OX10, Unisense A/S, Aarhus, Denmark). A total of 9 oxygen electrodes were used in this study, with an average response time of $0.33 \pm 0.11$ seconds ( $n=9$ probes). No compensation for the delay was performed. The oxygen electrodes were calibrated in air-saturated $0.9 \%$ sodium chloride (at $37^{\circ} \mathrm{C}$ ) and oxygen-free standard solution [0.1M sodium hydroxide (SX0607H-6, Sigma-Aldrich) and $0.1 \mathrm{M}$ sodium ascorbate (A7631, Sigma-Aldrich) in $0.9 \%$ sodium chloride] before and after each experiment. The linear drift of the oxygen electrode signal $(1.86 \pm 1.19 \%$ per hour) was corrected by linearly interpolating between pre- and post-experiment calibrations. The oxygen electrode was connected to a high-impedance picoammeter (OXYMeter, Unisense A/S, Aarhus, Denmark), whose output signals were digitalized at $1000 \mathrm{~Hz}$ (PCl-6259, National Instruments). Current recordings were transformed to millimeters of mercury $(\mathrm{mmHg})$ using the calibrations with air-saturated and oxygen-free solutions. 
Oxygen electrodes allow long-duration, quantitative measurements of the average oxygen tension from a small volume ( $20 \mu \mathrm{m}$ radius) of parenchymal tissue. And the stability of the electrode provides long duration measurements which are required to estimating the power at ultra-low frequencies. For oxygen polarography measurements, the oxygen microelectrode was positioned perpendicular to the brain surface and advanced into the cortex with a micromanipulator (MP-285, Sutter Instrument). Measurement site was chosen to avoid large pial vessels. The depth zero was defined as when the tip of the oxygen microelectrode touches the brain surface under visual inspection. The probe was then advanced to depth of $100,300,500$ and $800 \mu \mathrm{m}$ below the pia, and 30-40 minutes data were recorded for each depth. After advancing the electrode, we waited at least 5 minute before the start of each recording.

In experiments investigating effects of suppressing neural activity on cortical tissue oxygenation dynamics, a cocktail of ionotropic glutamate receptor antagonists 6-cyano-7nitroquinoxaline-2,3-dione (CNQX, $0.6 \mathrm{mM})$, NMDA receptor antagonist (2R)-amino-5phosphonopentanoic acid (AP5, $2.5 \mathrm{mM})$ and $\mathrm{GABA}_{\mathrm{A}}$ receptor agonist muscimol $(10 \mathrm{mM})$ were applied to suppress neural activity. All drugs were applied topically over the craniotomy and were 472 allowed to diffuse into the cortical tissue for at least $90 \mathrm{~min}$ before the oxygen measurements. 473 The efficacy of the CNQX/AP5/muscimol cocktail was validated with simultaneously recorded 474 neural activity. Neural data were amplified 1000x and filtered $(0.1$ - 10k Hz, DAM80, World 475 Precision Instruments) and then sampled at 30k Hz (PCl-6259, National Instruments). The oxygen 476 signal in these experiments was recorded at a depth of $\sim 100-200 \mu \mathrm{m}$.

In experiments investigating effects of suppressing neural activity on cortical tissue oxygenation dynamics, respiration was also simultaneously recorded. Measurements of breathing were taken using 40-guage K-type thermocouples (TC-TT-K-40-36, Omega Engineering) placed $4812000 x$, filtered below $30 \mathrm{~Hz}$ (Model 440, Brownlee Precision), and sampled at $1000 \mathrm{~Hz}$ (PCl-6259,

482 National Instruments). Downward and upward deflections in respiration recordings correspond to 483 inspiratory and expiratory phases of the respiratory cycle, respectively. We identified the time of 484 each expiratory peak in the entire record as the zero-crossing point of the first derivative of the 485 thermocouple signal.

At the end of the experiment, the mouse was deeply anesthetized, and a fiduciary mark was made by advancing an electrode (0.005" stainless steel wire, catalog \#794800, A-M systems) into the brain with a micro-manipulator to mark the oxygen measurement site. 
Laminar electrophysiology. Laminar electrophysiology recordings were performed in a separate set of mice $(n=6)$. On the day of measurement, the mouse was anesthetized using isoflurane (in oxygen, $5 \%$ for induction and $2 \%$ for maintenance). Two small $\left(1 \times 1 \mathrm{~mm}^{2}\right)$ craniotomies were performed over the frontal cortex (1.0 to $2.5 \mathrm{~mm}$ rostral and 1.0 to $2.5 \mathrm{~mm}$ lateral from bregma) and $\mathrm{FL} / \mathrm{HL}$ representation in the somatosensory cortex $(0.5$ to $1.0 \mathrm{~mm}$ caudal and 1.0 to $2.5 \mathrm{~mm}$ lateral from bregma) over the contralateral hemisphere, and the dura was carefully removed. The craniotomies were then moistened with warm saline and porcine gelatin (Vetspon). After this short surgical procedure ( 20 minutes), the mouse was then transferred to the treadmill where it was head-fixed. Measurements started at least one hour after the cessation of anesthesia [95, 153].

Neural activity signals were recorded using two linear microelectrode arrays (A1x16-3mm100-703-A16, NeuroNexus Technologies). The electrode array consisted of a single shank with 16 individual electrodes with $100 \mu \mathrm{m}$ inter-electrode spacing. The signals were digitalized and streamed to SmartBox ${ }^{\mathrm{TM}}$ via a SmartLink headstage (NeuroNexus Technologies). The arrays were positioned perpendicular to the cortical surface, one was in the FL/HL and the other one was in the FC on the contralateral side. Recording depth was inferred from manipulator (MP-285, Sutter Instrument) recordings. The neural signals were filtered (0.1-10k Hz bandpass), sampled at $20 \mathrm{k} \mathrm{Hz}$ using SmartBox 2.0 software (NeuroNexus Technologies).

Measuring RBC spacing in capillaries using $2 P L S M$. Two-photon imaging was performed with a Sutter Moveable Objective Microscope. A MaiTai HP (Spectra-Physics, Santa Clara, CA) laser tuned to $800 \mu \mathrm{m}$ was used for fluorophore excitation. Before imaging, the mouse was briefly anesthetized with isoflurane (5\% in oxygen), retro-orbitally injected with $50 \mu \mathrm{L}$ of $70 \mathrm{kDa}$ fluorescein-conjugated dextran (Sigma-Aldrich) prepared at a concentration of $5 \%$ was done with a 20X, 1.0 NA objective (Olympus, XLUMPFLN). Control of 2PLSM and data acquisition was accomplished using MScan software (Sutter Instruments). All imaging with the

514 water-immersion lens was done with room temperature distilled water. Wide-field images were 515 collected to generate vascular maps of the entire window for navigational purposes. High516 resolution images of the vasculature were collected using a 500 by $500 \mu \mathrm{m}$ field for measurement 517 of capillary diameter. Capillary diameter was measured using ImageJ. To measure RBC velocity 518 and RBC spacing, line scan images were collected from individual capillaries. RBCs appeared as 519 tilted dark shadows on a bright background due to the fluorescein-conjugated dextran contained 520 in the blood plasma (Figure 7a), and these shadows were counted. 
521 Data analysis. All data analyses were performed in Matlab (R2015b, MathWorks) using custom

522 code.

523 Locomotion events identification. Locomotion events [20, 24, 30, 154] from the spherical treadmill

524 were identified by first applying a low-pass filter $\left(10 \mathrm{~Hz}, 5^{\text {th }}\right.$ order Butterworth) to the velocity signal

525 from the optical rotary encoder, and then the absolute value of acceleration (first derivative of the

526 velocity signal) was thresholded at $3 \mathrm{~cm} / \mathrm{s}^{2}$. Periods of locomotion were categorized based on the

527 binarized detection of the treadmill acceleration:

$$
\delta(t)=H\left(\left|a_{t}\right|-a_{c}\right)= \begin{cases}1, & \left|a_{t}\right| \geq a_{c} \\ 0, & \left|a_{t}\right|<a_{c}\end{cases}
$$

529 where $a_{t}$ is the acceleration at time t, and $a_{c}$ is the treadmill acceleration threshold.

530 Spontaneous activity. To characterize spontaneous (non-locomotion-evoked) activity, we defined

531 "resting" periods as periods at least 4 seconds after the end of previous locomotion event and 532 lasting no less than 60 seconds.

533 Oxygen data preprocessing. Oxygen data from polarographic electrodes were first low-pass 534 filtered $\left(1 \mathrm{~Hz}, 5^{\text {th }}\right.$ order Butterworth). The oxygen data were then down-sampled to $30 \mathrm{~Hz}$ to align with binarized locomotion events.

Laminar neural activity. The neural signal was first digital filtered to obtain the local field potential (LFP, 0.1-300 Hz, $5^{\text {th }}$ order Butterworth) and multiunit activity (MUA, 300-3000 Hz, $5^{\text {th }}$ order techniques (Chronux toolbox version 2.11, http://chronux.org/) [103]. The power spectrum was estimated with a 1 second window with $\sim 1 \mathrm{~Hz}$ bandwidth averaged over nine tapers. MUA signals were low-pass filtered ( $5 \mathrm{~Hz}$, Bessel filter). The locomotion-evoked LFP power spectrum was converted into relative power spectrum by normalizing to the 3 second resting period prior to the onset of locomotion. Spike rate was obtained by counting the numbers of events that exceed an amplitude threshold (three standard deviations above background) in each 1 millisecond bin. third-order Butterworth filter to apply zero-phase bandpass filtering to the raw LFP according to 547 the following frequency bands: sub-alpha, 1-8 Hz; beta, 10-30 Hz; and gamma: 40-100 Hz. The 548 resulting BLP signals were squared and full-wave rectified. They were then resampled to $20 \mathrm{~Hz}$ 549 after low-pass filtering below $1 \mathrm{~Hz}$. These steps are illustrated in (Figure 3b and c). 
The spike train were extracted from each channel of the laminar electrode. Firing-rate signals in these data were smoothed with a Gaussian kernel with FWHM of $10 \mathrm{~ms}$ to generate a

552 continuous signal.

553 Magnitude-squared coherence. We used coherence analysis [155] to reveal correlated 554 oscillations and deduce functional coupling among different signals. The magnitude squared 555 ordinary coherence between two signals $\mathrm{x}$ and $\mathrm{y}$ are defined as

$$
C_{x y}^{2}(f)=\frac{S_{x y}^{2}(f)}{s_{x}(f) S_{y}(f)}
$$
spectrum.

Quantifying the oxygen fluctuations predicted by the neural activity. We considered the neurovascular relationship to be a linear time invariant system $[37,156,157]$. To provide a modelfree approach to assess the relationship between tissue oxygenation and neural activity, hemodynamic response function (HRF) was calculated by deconvoluting tissue oxygenation signal to gamma-band LFP power, using the following equation:

$$
\mathrm{H}_{(\mathrm{k}+1) \times 1}=\left(\mathrm{L}^{\mathrm{T}} \mathrm{L}\right)^{-1} \mathrm{~L}^{\mathrm{T}} \mathrm{V}_{(\mathrm{m}+\mathrm{k}) \times 1}
$$
containing measurements of gamma-band LFP power $(n)$ :

$$
\mathrm{L}(\overrightarrow{\mathrm{n}})=\left(\begin{array}{cccccc}
1 & \mathrm{n}_{1} & 0 & 0 & \cdots & 0 \\
1 & \mathrm{n}_{2} & \mathrm{n}_{1} & 0 & \cdots & 0 \\
\vdots & \vdots & \mathrm{n}_{2} & \mathrm{n}_{1} & \cdots & \vdots \\
\vdots & \mathrm{n}_{\mathrm{k}} & \vdots & \mathrm{n}_{2} & \cdots & \mathrm{n}_{1} \\
\vdots & 0 & \mathrm{n}_{\mathrm{k}} & \vdots & \cdots & \mathrm{n}_{2} \\
\vdots & \vdots & \vdots & \mathrm{n}_{\mathrm{k}} & \ddots & \vdots \\
1 & 0 & 0 & 0 & \cdots & \mathrm{n}_{\mathrm{k}}
\end{array}\right)
$$
the observed data into two segments with equal length. We then calculated the HRF using the first half of the observed data. We smoothed the HRF using a Savitzky-Golay filter ( $3^{\text {rd }}$ order, 11-

571 point frame length). Next, we convolved the HRF with the gamma-band LFP power from the 572 second half, and estimated the oxygenation predicted by neural activity using the following 573 equation, 
575 The efficacy of the prediction was quantified by calculating the correlation coefficient (R) between

576 the prediction and actual oxygenation. The process was shown in Supplementary Figure 4.

577 Hemodynamic response function kernel fitting. To quantify the temporal features of HRF, the HRF

578 for tissue oxygenation was fitted using two gamma-variate fitting process [25, 37, 116-118] using

579 a gamma-variate function kernel of the following form,

$$
\operatorname{HRF}(\mathrm{t}, \mathrm{T}, \mathrm{W}, \mathrm{A})=A *\left(\frac{t}{T}\right)^{\alpha} * e^{\left(\frac{t-T}{-\beta}\right)}
$$

581 where $\alpha=(T / W)^{2} * 8.0 * \log (2.0), \beta=W^{2} /(T * 8.0 * \log (2.0))$. For modeling HRF using a

582 gamma-variate function kernel, we used a downhill simplex algorithm minimizing the sum square 583 difference between measured and predicted hemodynamics. The goodness of fit was quantified as $R^{2}=1-\frac{\sum\left(H R F_{\text {actual }}-H R F_{\text {model }}\right)^{2}}{\sum\left(H R F_{\text {actual }}-\overline{H R F}\right)^{2}}$, where $\overline{H R F}$ is the mean value of the actual HRF. The amplitude (A), time-to-peak ( $\mathrm{T}$ ) and full-width at half maximum $(\mathrm{W})$ of the kernel was then calculated.

Modeling RBC spacing effects on tissue oxygenation. We identified the location of each RBC using custom code written in MATLAB from line scan images using 2PLSM (Figure 7a). Data was first undergoing visual inspection to determine if the quality was sufficient for reliable RBC detection. To calculate the power spectral density of RBCs train, we estimated using a function specifically for point processes (Chronux toolbox function: mtspectrumsegpb). To estimate the $\mathrm{RBC}$ interval distribution, we pooled all observed $\mathrm{RBC}$ intervals during rest from different animals mice ([128], 0.5\%) and anesthetized mice ([92], 2.1\%), which makes the observation of capillaries with a cessation of RBC flow challenging. It is also not practical to measure a large number of capillaries with a sufficiently long duration to characterize the temporal dynamics using 2PLSM, 597 as it requires to focus on a limited number of segments with high magnification and a narrow field 598 of view. To avoid the bias of PDF estimation due to the rare occurrence of "stall" events in our 599 experiments, we also estimated the PDF of "stall" events using data from [128]. Combining these 600 two PDFs, we estimated a new PDF of RBC intervals to generate a synthetic dataset (matlab 601 function: normrnd). As the consecutive RBC intervals are not totally random and has a power law 602 slope close to 1 (Figure $7 \mathrm{~b}$ ), we introduced long-range autocorrelation using inverse Fourier 603 transform. 
606 in single file, separated by plasma gaps of variable lengths, therefore, the capillary blood is not a 607 homogenous oxygen source, but has heterogenic dynamics. We therefore assumed that 1) the 608 tissue is primarily oxygenated by the nearest capillary. 2) The space between RBC and capillary 609 wall is minimal, and that the capillary wall does not hinder the transport of oxygen. Therefore, the 610 oxygen concentration profile is continuous between blood and tissue. 3) Oxygen transport within 611 the tissue is assumed to be solely by molecular diffusion and governed by Fick's second law of 612 diffusion. 4) The rate of consumption of oxygen by the tissue surrounding the capillary is constant. 613 Under these assumptions, over time, the level of oxygen within the tissue rises until the amount 614 of oxygen lost by the passing cells converges to a quasi-steady level. At this quasi-steady state, 615 the oxygen level in the proximity of the capillary fluctuates between a maximum reached just after 616 the passage of a RBC and a minimum midway prior to the arrival of the next RBC (Figure 7e and $617 \mathrm{f}$ ). The amount of oxygen delivered by a RBC to the tissue slice is the summation of the oxygen 618 mass gained and consumed within the tissue during its residence.

619 To keep the model tractable, the geometry of the erythrocytes was not considered (for a 620 complete model, see [81]), and the erythrocyte as an oxygen source is kept as a point-like oxygen 621 source [68]. The oxygen tension for each RBC was set to be the same, and the diffusion of oxygen 622 from RBC to plasma was simulated with an exponential decay kernel measured in previous 623 experiments [83-86].

To model tissue oxygen responses, we simulated a vessel with $3 \mu \mathrm{m}$ radius and a tissue cylinder of $20 \mu \mathrm{m}$ radius using Krogh cylinder model.

$$
\mathrm{PtO} 2=\mathrm{PwO} 2+\frac{C M R O 2}{4 \alpha_{t} D_{t}}\left(r^{2}-R^{2}-2 R t^{2} \ln \left(\frac{r}{R}\right)\right)
$$

Where, $D_{t}=2800 \mu \mathrm{m}^{2} / \mathrm{s}$ [158], $\alpha_{\mathrm{t}}=1.39 \mu \mathrm{M} / \mathrm{mmHg}$ [159], $\mathrm{CMRO} 2=3 \mu \mathrm{mole} / \mathrm{cm}^{3} / \mathrm{min}$

628 [160]. As the transit time of RBCs is much faster than the tissue response time, the observed 629 oxygenation is further smoothed using the response time, which is given by $R^{2} \ln \left(\frac{r}{R}\right) /\left(2 D_{t}\right)[73]$. $630 \mathrm{R}$ is the outer radius and $\mathrm{r}$ is the ratio of outer to inner radii. In this way, oxygen delivery from 631 capillaries decays rapidly with distance. As the oxygen probe samples a small region around the 632 tip, we averaged tissue oxygen data within $10 \mu \mathrm{m}$ away from the location of the probe. Finally, to 633 account for the response time of the polarographic oxygen electrodes [20], we smoothed the 634 averaged oxygen trace with a low pass filter. 
635

636

637

638

639

640

641

642

643

644

645

646

647

648

649

650

651

652

653

654

655

656

657

658

659

660

661

662

663

664

665

666

667

White noise, 1/f noise and periodic noise. To test the suitability of power spectral analysis as a method to estimate power-law scales of the same length as the signals used in our analysis, we simulated time series with a stochastic Gaussian process of known long-range temporal dependence (fractional Gaussian noise). The power spectra of different types of signals are shown in Figure 1. White noise (Figure 1a) has a flat power spectrum whose slope is near 0. Periodic noise (Figure 1b) shows a flat spectrum, with the exception of a large bump at $0.2 \mathrm{~Hz}$, the center frequency of the large oscillations. In contrast, 1/f-like noise, generated using a circulant embedding method [161], shows power decreasing with frequency when the power spectrum is plotted on a log-log scale (Figure 1c). Summation of a periodic signal with a 1/f-like signal produces a hybrid spectrum (Figure 1d).

Power spectral density and power-law exponent. The power spectrum density (PSD) was obtained using the multitaper technique [103]. As brain activity fluctuations have been observed to have a $1 / \mathrm{f}$ power spectrum [162], we tried to fit the power spectrum of oxygen signal with a power-law distribution using least squares fit. However, when linearly-spaced frequency bins are considered under a logarithmic scale, bins in higher-frequencies become progressively denser, and thus gain disproportionate weight with respect to lower frequency-bins in a sub-sequent linear regression. To avoid this potential bias, we upsampled the PSD curve with logarithmically spaced frequency bins, resulting in equally-spaced frequency bins under logarithmic scale, required to properly estimate the spectral exponent. We then used the simple linear regression to the resampled PSD in order to increase comparability to other studies $[8,58]$.

Although the power spectrum analysis for $1 / f-$ like dynamics estimation is widely used [8, $58,59,65,162]$, it is important to note that the validity of the applied method has also been criticized [163]. Touboul and Destexhe [163] argue that the power law underlying the $1 / \mathrm{f}$ method may not necessarily reflect neurophysiological processes, but could simply arise from purely stochastic mechanisms. Although problematic in testing for the existence of power-law behavior [109], this power spectrum density method gives a good estimate in cases in which the powerlaw behavior is clear enough [164], or when the aim is at approximating the functional relation rather than setting its exact form, as presented in this study and previous studies $[165,166]$.

Control recordings and analyses. Because fluctuations of resistivity in electronic conducting materials also exhibit $1 / \mathrm{f}$ noise [108], it is important to demonstrate that our data were not contributed by instrument noise. To address this, we measured $\mathrm{PtO}_{2}$ in one dead mouse using the same experimental setup. The power spectrum of these recordings had flat slope $(\sim 0)$ characteristic of white noise (Figure $2 \mathrm{~d}$ ). 
668 Statistical analysis. Statistical analysis was performed using Matlab. All summary data were 669 reported as the mean \pm standard deviation (SD) unless stated otherwise. Normality of the samples 670 were tested before statistical testing using Anderson-Darling test (adtest). For comparison of 671 multiple populations, the assumption of equal variance for parametric statistical method was also 672 tested (vartest2 and vartestn). If criteria of normality and equal variance were not met, parametric 673 tests (t test, one-way ANOVA) were replaced with a nonparametric method (Mann-Whiteney U674 test, Wilcoxon signed-rank test, Kruskal-Wallis ANOVA). All $p$ values were Bonferroni corrected 675 for multiple comparisons. Significance was accepted at $p<0.05$. 


\section{References}

677 1. Braun RD, Lanzen JL, Dewhirst MW. Fourier analysis of fluctuations of oxygen tension and blood flow in R3230Ac tumors and muscle in rats. Am J Physiol. 1999;277(2 Pt 2):H551-68. PubMed PMID: 10444480.

2. Braun RD, Linsenmeier RA, Yancey CM. Spontaneous fluctuations in oxygen tension in the cat retina. Microvasc Res. 1992;44(1):73-84. PubMed PMID: 1640880.

3. Riva CE, Pournaras CJ, Poitry-Yamate CL, Petrig BL. Rhythmic changes in velocity, volume, and flow of blood in the optic nerve head tissue. Microvasc Res. 1990;40(1):36-45. PubMed PMID: 2144606.

4. Purves MJ. Fluctuations of arterial oxygen tension which have the same period as respiration. Respir Physiol. 1966;1(3):281-96. PubMed PMID: 5968345.

5. Manil J, Bourgain RH, Van Waeyenberge M, Colin F, Blockeel E, De Mey B, et al. Properties of the spontaneous fluctuations in cortical oxygen pressure. Adv Exp Med Biol. 1984;169:231-9. PubMed PMID: 6145312.

690 6. Hudetz AG, Biswal BB, Shen H, Lauer KK, Kampine JP. Spontaneous fluctuations in 691 cerebral oxygen supply. An introduction. Adv Exp Med Biol. 1998;454:551-9. PubMed PMID: 6929889935.

693 7. Linsenmeier RA, Aksenov DP, Faber HM, Makar P, Wyrwicz AM. Spontaneous

694 Fluctuations of PO2 in the Rabbit Somatosensory Cortex. Adv Exp Med Biol. 2016;876:311-7. doi: 10.1007/978-1-4939-3023-4_39. PubMed PMID: 26782227.

8. Li JM, Bentley WJ, Snyder LH. Functional connectivity arises from a slow rhythmic mechanism. Proc Natl Acad Sci U S A. 2015;112(19):E2527-35. doi:

10.1073/pnas.1419837112. PubMed PMID: 25918427; PubMed Central PMCID: PMCPMC4434692.

700 9. Padnick LB, Linsenmeier RA, Goldstick TK. Oxygenation of the cat primary visual cortex.

701 J Appl Physiol (1985). 1999;86(5):1490-6. PubMed PMID: 10233109.

702 10. Li J, Martin S, Tricklebank MD, Schwarz AJ, Gilmour G. Task-induced modulation of 703 intrinsic functional connectivity networks in the behaving rat. J Neurosci. 2015;35(2):658-65. doi: 10.1523/JNEUROSCI.3488-14.2015. PubMed PMID: 25589760.

\section{Cooper R, Crow HJ, Walter WG, Winter AL. Regional control of cerebral vascular} reactivity and oxygen supply in man. Brain Res. 1966;3(2):174-91. PubMed PMID: 5971521. 12. Obrig H, Neufang M, Wenzel R, Kohl M, Steinbrink J, Einhaupl K, et al. Spontaneous low frequency oscillations of cerebral hemodynamics and metabolism in human adults. Neuroimage. 2000;12(6):623-39. doi: 10.1006/nimg.2000.0657. PubMed PMID: 11112395. 13. Birn RM, Diamond JB, Smith MA, Bandettini PA. Separating respiratory-variation-related fluctuations from neuronal-activity-related fluctuations in fMRI. Neuroimage. 2006;31(4):153648. doi: 10.1016/j.neuroimage.2006.02.048. PubMed PMID: 16632379.

14. Birn RM, Murphy K, Bandettini PA. The effect of respiration variations on independent component analysis results of resting state functional connectivity. Hum Brain Mapp.

2008;29(7):740-50. doi: 10.1002/hbm.20577. PubMed PMID: 18438886; PubMed Central PMCID: PMCPMC2715870.

15. Birn RM, Smith MA, Jones TB, Bandettini PA. The respiration response function: the temporal dynamics of $\mathrm{fMRI}$ signal fluctuations related to changes in respiration. Neuroimage. 2008;40(2):644-54. doi: 10.1016/j.neuroimage.2007.11.059. PubMed PMID: 18234517; PubMed Central PMCID: PMCPMC2533266.

16. Birn RM, Murphy K, Handwerker DA, Bandettini PA. fMRI in the presence of taskcorrelated breathing variations. Neuroimage. 2009;47(3):1092-104. doi: 10.1016/j.neuroimage.2009.05.030. PubMed PMID: 19460443; PubMed Central PMCID: PMCPMC2998293. 
17. Power JD, Plitt M, Laumann TO, Martin A. Sources and implications of whole-brain fMRI signals in humans. Neuroimage. 2017;146:609-25. doi: 10.1016/j.neuroimage.2016.09.038. PubMed PMID: 27751941; PubMed Central PMCID: PMCPMC5321814. 18. Power JD, Plitt M, Gotts SJ, Kundu P, Voon V, Bandettini PA, et al. Ridding fMRI data of motion-related influences: Removal of signals with distinct spatial and physical bases in multiecho data. Proc Natl Acad Sci U S A. 2018;115(9):E2105-E14. doi: 10.1073/pnas.1720985115. PubMed PMID: 29440410; PubMed Central PMCID: PMCPMC5834724.

19. Power JD, Lynch CJ, Silver BM, Dubin MJ, Martin A, Jones RM. Distinctions among real and apparent respiratory motions in human fMRI data. Neuroimage. 2019;201:116041. doi: 10.1016/j.neuroimage.2019.116041. PubMed PMID: 31344484; PubMed Central PMCID: PMCPMC6765416.

20. Zhang Q, Roche M, Gheres KW, Chaigneau E, Kedarasetti RT, Haselden WD, et al. Cerebral oxygenation during locomotion is modulated by respiration. Nature Communications. 2019;10(1). doi: 10.1038/s41467-019-13523-5.

21. Stumpf MP, Porter MA. Mathematics. Critical truths about power laws. Science. 2012;335(6069):665-6. doi: 10.1126/science.1216142. PubMed PMID: 22323807.

22. Kim SG, Ogawa S. Biophysical and physiological origins of blood oxygenation leveldependent fMRI signals. J Cereb Blood Flow Metab. 2012;32(7):1188-206. doi: 10.1038/jcbfm.2012.23. PubMed PMID: 22395207; PubMed Central PMCID: PMCPMC3390806.

23. Logothetis NK. What we can do and what we cannot do with fMRI. Nature. 2008;453(7197):869-78. doi: 10.1038/nature06976. PubMed PMID: 18548064.

24. Huo BX, Smith JB, Drew PJ. Neurovascular coupling and decoupling in the cortex during voluntary locomotion. J Neurosci. 2014;34(33):10975-81. doi: 10.1523/JNEUROSCI.136914.2014. PubMed PMID: 25122897; PubMed Central PMCID: PMCPMC4131012.

25. Sirotin YB, Das A. Anticipatory haemodynamic signals in sensory cortex not predicted by local neuronal activity. Nature. 2009;457(7228):475-9. doi: 10.1038/nature07664. PubMed PMID: 19158795; PubMed Central PMCID: PMCPMC2705195.

26. Shih YY, Wey HY, De La Garza BH, Duong TQ. Striatal and cortical BOLD, blood flow, blood volume, oxygen consumption, and glucose consumption changes in noxious forepaw electrical stimulation. J Cereb Blood Flow Metab. 2011;31(3):832-41. doi: 10.1038/jcbfm.2010.173. PubMed PMID: 20940730; PubMed Central PMCID: PMCPMC3063626.

27. Mishra AM, Ellens DJ, Schridde U, Motelow JE, Purcaro MJ, DeSalvo MN, et al. Where $\mathrm{fMRI}$ and electrophysiology agree to disagree: corticothalamic and striatal activity patterns in the WAG/Rij rat. J Neurosci. 2011;31(42):15053-64. doi: 10.1523/JNEUROSCI.0101-11.2011. PubMed PMID: 22016539; PubMed Central PMCID: PMCPMC3432284.

28. Maier A, Wilke M, Aura C, Zhu C, Ye FQ, Leopold DA. Divergence of fMRI and neural signals in V1 during perceptual suppression in the awake monkey. Nat Neurosci. 2008;11(10):1193-200. doi: 10.1038/nn.2173. PubMed PMID: 18711393; PubMed Central PMCID: PMCPMC2754054.

29. Devor A, Hillman EM, Tian P, Waeber C, Teng IC, Ruvinskaya L, et al. Stimulus-induced changes in blood flow and 2-deoxyglucose uptake dissociate in ipsilateral somatosensory cortex. J Neurosci. 2008;28(53):14347-57. doi: 10.1523/JNEUROSCI.4307-08.2008. PubMed PMID: 19118167; PubMed Central PMCID: PMCPMC2655308.

30. Winder AT, Echagarruga C, Zhang Q, Drew PJ. Weak correlations between hemodynamic signals and ongoing neural activity during the resting state. Nat Neurosci. 2017;20(12):1761-9. doi: 10.1038/s41593-017-0007-y. PubMed PMID: 29184204. 31. Mateo C, Knutsen PM, Tsai PS, Shih AY, Kleinfeld D. Entrainment of Arteriole Vasomotor Fluctuations by Neural Activity Is a Basis of Blood-Oxygenation-Level-Dependent 
"Resting-State" Connectivity. Neuron. 2017;96(4):936-48 e3. doi: 10.1016/j.neuron.2017.10.012. PubMed PMID: 29107517; PubMed Central PMCID: PMCPMC5851777.

32. Logothetis NK, Pauls J, Augath M, Trinath T, Oeltermann A. Neurophysiological investigation of the basis of the fMRI signal. Nature. 2001;412(6843):150-7. doi: 10.1038/35084005. PubMed PMID: 11449264.

33. Niessing J, Ebisch B, Schmidt KE, Niessing M, Singer W, Galuske RA. Hemodynamic signals correlate tightly with synchronized gamma oscillations. Science. 2005;309(5736):94851. doi: 10.1126/science.1110948. PubMed PMID: 16081740.

34. Scholvinck ML, Maier A, Ye FQ, Duyn JH, Leopold DA. Neural basis of global restingstate fMRI activity. Proc Natl Acad Sci U S A. 2010;107(22):10238-43. doi: 10.1073/pnas.0913110107. PubMed PMID: 20439733; PubMed Central PMCID: PMCPMC2890438.

35. Magri C, Schridde U, Murayama Y, Panzeri S, Logothetis NK. The amplitude and timing of the BOLD signal reflects the relationship between local field potential power at different frequencies. J Neurosci. 2012;32(4):1395-407. doi: 10.1523/JNEUROSCI.3985-11.2012. PubMed PMID: 22279224.

36. Drew PJ, Mateo C, Turner KL, Yu X, Kleinfeld D. Ultra-slow Oscillations in fMRI and Resting-State Connectivity: Neuronal and Vascular Contributions and Technical Confounds. Neuron. 2020. doi: 10.1016/j.neuron.2020.07.020. PubMed PMID: 32791040.

37. Cardoso MM, Sirotin YB, Lima B, Glushenkova E, Das A. The neuroimaging signal is a linear sum of neurally distinct stimulus- and task-related components. Nat Neurosci. 2012;15(9):1298-306. doi: 10.1038/nn.3170. PubMed PMID: 22842146; PubMed Central PMCID: PMCPMC3690535.

38. Lima B, Cardoso MM, Sirotin YB, Das A. Stimulus-related neuroimaging in task-engaged subjects is best predicted by concurrent spiking. J Neurosci. 2014;34(42):13878-91. doi: 10.1523/JNEUROSCI.1595-14.2014. PubMed PMID: 25319685; PubMed Central PMCID: PMCPMC4198534.

39. Mitra A, Kraft A, Wright P, Acland B, Snyder AZ, Rosenthal Z, et al. Spontaneous Infraslow Brain Activity Has Unique Spatiotemporal Dynamics and Laminar Structure. Neuron. 2018;98(2):297-305 e6. doi: 10.1016/j.neuron.2018.03.015. PubMed PMID: 29606579; PubMed Central PMCID: PMCPMC5910292.

40. He BJ, Raichle ME. The fMRI signal, slow cortical potential and consciousness. Trends Cogn Sci. 2009;13(7):302-9. doi: 10.1016/j.tics.2009.04.004. PubMed PMID: 19535283; PubMed Central PMCID: PMCPMC2855786.

41. He BJ, Snyder AZ, Zempel JM, Smyth MD, Raichle ME. Electrophysiological correlates of the brain's intrinsic large-scale functional architecture. Proc Natl Acad Sci U S A. 2008;105(41):16039-44. doi: 10.1073/pnas.0807010105. PubMed PMID: 18843113; PubMed Central PMCID: PMCPMC2564983.

42. Held D, Fencl V, Pappenheimer JR. Electrical Potential of Cerebrospinal Fluid. J Neurophysiol. 1964;27:942-59. doi: 10.1152/jn.1964.27.5.942. PubMed PMID: 14205013. 43. Sorensen SC, Severinghaus JW. Effect of cerebral acidosis on the CSF-blood potential difference. Am J Physiol. 1970;219(1):68-71. doi: 10.1152/ajplegacy.1970.219.1.68. PubMed PMID: 5424860.

44. Drew PJ, Shih AY, Kleinfeld D. Fluctuating and sensory-induced vasodynamics in rodent cortex extend arteriole capacity. Proc Natl Acad Sci U S A. 2011;108(20):8473-8. doi: 10.1073/pnas.1100428108. PubMed PMID: 21536897; PubMed Central PMCID: PMCPMC3100929.

45. Huo BX, Gao YR, Drew PJ. Quantitative separation of arterial and venous cerebral blood volume increases during voluntary locomotion. Neuroimage. 2015;105:369-79. doi: 
10.1016/j.neuroimage.2014.10.030. PubMed PMID: 25467301; PubMed Central PMCID: PMCPMC4330110.

46. Pisauro MA, Dhruv NT, Carandini M, Benucci A. Fast hemodynamic responses in the visual cortex of the awake mouse. J Neurosci. 2013;33(46):18343-51. doi: 10.1523/JNEUROSCI.2130-13.2013. PubMed PMID: 24227743; PubMed Central PMCID: PMCPMC3828474.

47. Vanhatalo S, Tallgren P, Becker C, Holmes MD, Miller JW, Kaila K, et al. Scalp-recorded slow EEG responses generated in response to hemodynamic changes in the human brain. Clinical Neurophysiology. 2003;114(9):1744-54. doi: 10.1016/S1388-2457(03)00163-9. 48. Besson JM, Woody CD, Aleonard P, Thompson HK, Albe-Fessard D, Marshall WH. Correlations of brain d-c shifts with changes in cerebral blood flow. Am J Physiol. 1970;218(1):284-91. doi: 10.1152/ajplegacy.1970.218.1.284. PubMed PMID: 4982913. 49. Nita DA, Vanhatalo S, Lafortune FD, Voipio J, Kaila K, Amzica F. Nonneuronal origin of CO2-related DC EEG shifts: an in vivo study in the cat. J Neurophysiol. 2004;92(2):1011-22. doi: 10.1152/jn.00110.2004. PubMed PMID: 15056689.

50. Voipio J, Tallgren P, Heinonen E, Vanhatalo S, Kaila K. Millivolt-scale DC shifts in the human scalp EEG: evidence for a nonneuronal generator. Journal of neurophysiology. 2003;89(4):2208-14. doi: 10.1152/jn.00915.2002.

51. Ngai AC, Winn HR. Estimation of shear and flow rates in pial arterioles during somatosensory stimulation. Am J Physiol. 1996;270(5 Pt 2):H1712-7. doi: 10.1152/ajpheart.1996.270.5.H1712. PubMed PMID: 8928878.

52. de Cheveigne A, Nelken I. Filters: When, Why, and How (Not) to Use Them. Neuron. 2019;102(2):280-93. doi: 10.1016/j.neuron.2019.02.039. PubMed PMID: 30998899.

53. Thompson JK, Peterson MR, Freeman RD. Separate spatial scales determine neural activity-dependent changes in tissue oxygen within central visual pathways. J Neurosci. 2005;25(39):9046-58. doi: 10.1523/JNEUROSCI.2127-05.2005. PubMed PMID: 16192396. 54. Li B, Freeman RD. High-resolution neurometabolic coupling in the lateral geniculate nucleus. J Neurosci. 2007;27(38):10223-9. doi: 10.1523/JNEUROSCI.1505-07.2007. PubMed PMID: 17881528.

55. Viswanathan A, Freeman RD. Neurometabolic coupling in cerebral cortex reflects synaptic more than spiking activity. Nat Neurosci. 2007;10(10):1308-12. doi: 10.1038/nn1977. PubMed PMID: 17828254.

56. Thompson JK, Peterson MR, Freeman RD. Single-neuron activity and tissue oxygenation in the cerebral cortex. Science. 2003;299(5609):1070-2. doi: 10.1126/science.1079220. PubMed PMID: 12586942.

57. Bentley WJ, Li JM, Snyder AZ, Raichle ME, Snyder LH. Oxygen Level and LFP in TaskPositive and Task-Negative Areas: Bridging BOLD fMRI and Electrophysiology. Cereb Cortex. 2016;26(1):346-57. doi: 10.1093/cercor/bhu260. PubMed PMID: 25385710; PubMed Central PMCID: PMCPMC4677981.

58. He BJ. Scale-free properties of the functional magnetic resonance imaging signal during rest and task. J Neurosci. 2011;31(39):13786-95. doi: 10.1523/JNEUROSCI.2111-11.2011. PubMed PMID: 21957241; PubMed Central PMCID: PMCPMC3197021. 59. He BJ, Zempel JM, Snyder AZ, Raichle ME. The temporal structures and functional significance of scale-free brain activity. Neuron. 2010;66(3):353-69. doi: 10.1016/j.neuron.2010.04.020. PubMed PMID: 20471349; PubMed Central PMCID: PMCPMC2878725.

60. Bullmore E, Fadili J, Breakspear M, Salvador R, Suckling J, Brammer M. Wavelets and statistical analysis of functional magnetic resonance images of the human brain. Stat Methods Med Res. 2003;12(5):375-99. doi: 10.1191/0962280203sm339ra. PubMed PMID: 14599002. 
875

876

877

878

879

880

881

882

883

884

885

886

887

888

889

890

891

892

893

894

895

896

897

898

899

900

901

902

903

904

905

906

907

908

909

910

911

912

913

914

915

916

917

918

919

920

921

922

923

924

61. Fox MD, Raichle ME. Spontaneous fluctuations in brain activity observed with functional magnetic resonance imaging. Nat Rev Neurosci. 2007;8(9):700-11. doi: 10.1038/nrn2201. PubMed PMID: 17704812.

62. Schirner M, Mclntosh AR, Jirsa V, Deco G, Ritter P. Inferring multi-scale neural mechanisms with brain network modelling. Elife. 2018;7. doi: 10.7554/eLife.28927. PubMed PMID: 29308767; PubMed Central PMCID: PMCPMC5802851.

63. Wen H, Liu Z. Broadband Electrophysiological Dynamics Contribute to Global RestingState fMRI Signal. J Neurosci. 2016;36(22):6030-40. doi: 10.1523/JNEUROSCI.0187-16.2016. PubMed PMID: 27251624; PubMed Central PMCID: PMCPMC4887567.

64. Nir Y, Mukamel R, Dinstein I, Privman E, Harel M, Fisch L, et al. Interhemispheric correlations of slow spontaneous neuronal fluctuations revealed in human sensory cortex. Nature Neuroscience. 2008;11(9):1100-8. doi: 10.1038/nn.2177.

65. Leopold DA, Murayama Y, Logothetis NK. Very slow activity fluctuations in monkey visual cortex: implications for functional brain imaging. Cereb Cortex. 2003;13(4):422-33. PubMed PMID: 12631571.

66. Popel AS. Theory of oxygen transport to tissue. Crit Rev Biomed Eng. 1989;17(3):257321. PubMed PMID: 2673661; PubMed Central PMCID: PMCPMC5445261.

67. Barker MC, Golub AS, Pittman RN. Erythrocyte-associated transients in capillary PO2: an isovolemic hemodilution study in the rat spinotrapezius muscle. Am J Physiol Heart Circ Physiol. 2007;292(5):H2540-9. doi: 10.1152/ajpheart.00915.2006. PubMed PMID: 17277027. 68. Bos C, Hoofd L, Oostendorp T. Mathematical-Model of Erythrocytes as Point-Like Sources. Mathematical Biosciences. 1995;125(2):165-89. doi: Doi 10.1016/00255564(94)00026-V. PubMed PMID: WOS:A1995QC85900003.

69. Clark A, Federspiel WJ, Clark PA, Cokelet GR. Oxygen delivery from red cells. Biophysical Journal. 1985;47(2):171-81. doi: 10.1016/s0006-3495(85)83890-x.

70. Ellsworth ML, Popel AS, Pittman RN. Assessment and impact of heterogeneities of convective oxygen transport parameters in capillaries of striated muscle: experimental and theoretical. Microvasc Res. 1988;35(3):341-62. doi: 10.1016/0026-2862(88)90089-1. PubMed PMID: 3393095; PubMed Central PMCID: PMCPMC6124310.

71. Federspiel WJ, Sarelius IH. An examination of the contribution of red cell spacing to the uniformity of oxygen flux at the capillary wall. Microvasc Res. 1984;27(3):273-85. doi: 10.1016/0026-2862(84)90059-1. PubMed PMID: 6727699.

72. Golub AS, Pittman RN. Erythrocyte-associated transients in $\mathrm{PO} 2$ revealed in capillaries of rat mesentery. Am J Physiol Heart Circ Physiol. 2005;288(6):H2735-43. doi:

10.1152/ajpheart.00711.2004. PubMed PMID: 15695557.

73. Hellums JD. The resistance to oxygen transport in the capillaries relative to that in the surrounding tissue. Microvascular Research. 1977;13(1):131-6. doi: 10.1016/00262862(77)90122-4.

74. Hellums JD, Nair PK, Huang NS, Ohshima N. Simulation of intraluminal gas transport processes in the microcirculation. Ann Biomed Eng. 1996;24(1):1-24. doi: 10.1007/bf02770991. PubMed PMID: 8669708.

75. Homer LD, Weathersby PK, Kiesow LA. Oxygen gradients between red blood cells in the microcirculation. Microvascular Research. 1981;22(3):308-23. doi: 10.1016/00262862(81)90099-6.

76. Hoofd L, Bos C, Oostendorp T. The effect of blood flow on oxygen extraction pressures calculated in a model of pointlike erythrocyte sources for rat heart. Math Biosci. 1996;131(1):2349. doi: 10.1016/0025-5564(95)00009-7. PubMed PMID: 8589537.

77. Hoofd L, Bos C, Turek Z. Modeling Erythrocytes as Point-Like O2 Sources in a Kroghian Cylinder Model. Oxygen Transport to Tissue Xv. 1994;345:893-900. PubMed PMID:

WOS:A1994BA42S00117. 
925

926

927

928

929

930

931

932

933

934

935

936

937

938

939

940

941

942

943

944

945

946

947

948

949

950

951

952

953

954

955

956

957

958

959

960

961

962

963

964

965

966

967

968

969

970

971

972

973

974

78. Pittman RN. Oxygen transport in the microcirculation and its regulation. Microcirculation. 2013;20(2):117-37. doi: 10.1111/micc.12017. PubMed PMID: 23025284; PubMed Central PMCID: PMCPMC3574207.

79. Reneau DD. A mathematical simulation of oxygen release, diffusion and consumption in the capillaries and tissue of the human brain [Dissertation]: Clemson University; 1967.

80. Varela FE, Popel AS. Effect of Intracapillary Resistance to Oxygen-Transport on the Diffusional Shunting between Capillaries. Journal of Biomedical Engineering. 1988;10(5):400-5. doi: Doi 10.1016/0141-5425(88)90142-2. PubMed PMID: WOS:A1988Q332200004.

81. Lucker A, Weber B, Jenny P. A dynamic model of oxygen transport from capillaries to tissue with moving red blood cells. Am J Physiol Heart Circ Physiol. 2015;308(3):H206-16. doi: 10.1152/ajpheart.00447.2014. PubMed PMID: 25398979.

82. Lucker A, Secomb TW, Weber B, Jenny $P$. The relative influence of hematocrit and red blood cell velocity on oxygen transport from capillaries to tissue. Microcirculation. 2017;24(3). doi: 10.1111/micc.12337. PubMed PMID: 27893186; PubMed Central PMCID: PMCPMC5404950.

83. Parpaleix A, Goulam Houssen Y, Charpak S. Imaging local neuronal activity by monitoring $\mathrm{PO}(2)$ transients in capillaries. Nat Med. 2013;19(2):241-6. doi: 10.1038/nm.3059. PubMed PMID: 23314058.

84. Lecoq J, Parpaleix A, Roussakis E, Ducros M, Goulam Houssen Y, Vinogradov SA, et al. Simultaneous two-photon imaging of oxygen and blood flow in deep cerebral vessels. Nat Med. 2011;17(7):893-8. doi: 10.1038/nm.2394. PubMed PMID: 21642977; PubMed Central PMCID: PMCPMC3291110.

85. Lyons DG, Parpaleix A, Roche M, Charpak S. Mapping oxygen concentration in the awake mouse brain. Elife. 2016;5. doi: 10.7554/eLife.12024. PubMed PMID: 26836304; PubMed Central PMCID: PMCPMC4775210.

86. Li B, Esipova TV, Sencan I, Kilic K, Fu B, Desjardins M, et al. More homogeneous capillary flow and oxygenation in deeper cortical layers correlate with increased oxygen extraction. Elife. 2019;8. doi: 10.7554/eLife.42299. PubMed PMID: 31305237; PubMed Central PMCID: PMCPMC6636997.

87. Cruz Hernandez JC, Bracko O, Kersbergen CJ, Muse V, Haft-Javaherian M, Berg M, et al. Neutrophil adhesion in brain capillaries reduces cortical blood flow and impairs memory function in Alzheimer's disease mouse models. Nat Neurosci. 2019;22(3):413-20. doi: 10.1038/s41593-018-0329-4. PubMed PMID: 30742116; PubMed Central PMCID: PMCPMC6508667.

88. Santisakultarm TP, Paduano CQ, Stokol T, Southard TL, Nishimura N, Skoda RC, et al. Stalled cerebral capillary blood flow in mouse models of essential thrombocythemia and polycythemia vera revealed by in vivo two-photon imaging. J Thromb Haemost. 2014;12(12):2120-30. doi: 10.1111/jth.12738. PubMed PMID: 25263265.

89. Kleinfeld D, Mitra PP, Helmchen F, Denk W. Fluctuations and stimulus-induced changes in blood flow observed in individual capillaries in layers 2 through 4 of rat neocortex. Proc Natl Acad Sci U S A. 1998;95(26):15741-6. doi: 10.1073/pnas.95.26.15741. PubMed PMID: 9861040; PubMed Central PMCID: PMCPMC28114.

90. Villringer A, Them A, Lindauer U, Einhaupl K, Dirnagl U. Capillary perfusion of the rat brain cortex. An in vivo confocal microscopy study. Circ Res. 1994;75(1):55-62. doi: 10.1161/01.res.75.1.55. PubMed PMID: 8013082.

91. Reeson $P$, Choi K, Brown CE. VEGF signaling regulates the fate of obstructed capillaries in mouse cortex. Elife. 2018;7. doi: 10.7554/eLife.33670. PubMed PMID: 29697373; PubMed Central PMCID: PMCPMC5919759.

92. Hyacinth HI, Sugihara CL, Spencer TL, Archer DR, Shih AY. Higher prevalence of spontaneous cerebral vasculopathy and cerebral infarcts in a mouse model of sickle cell 
975

976

977

978

979

980

981

982

983

984

985

986

987

988

1011

1012

1013

1014

1015

1016

1017

1018

1019

1020

1021

1022

1023

1024

disease. J Cereb Blood Flow Metab. 2019;39(2):342-51. doi: 10.1177/0271678X17732275. PubMed PMID: 28925802; PubMed Central PMCID: PMCPMC6365608.

93. Warnke KC, Skalak TC. Leukocyte plugging in vivo in skeletal muscle arteriolar trees. Am J Physiol. 1992;262(4 Pt 2):H1149-55. doi: 10.1152/ajpheart.1992.262.4.H1149. PubMed PMID: 1566897.

94. Erdener SE, Tang J, Kilic K, Postnov D, Giblin JT, Kura S, et al. Dynamic capillary stalls in reperfused ischemic penumbra contribute to injury: A hyperacute role for neutrophils in persistent traffic jams. J Cereb Blood Flow Metab. 2020:271678X20914179. doi: 10.1177/0271678X20914179. PubMed PMID: 32237951.

95. Gao YR, Ma Y, Zhang Q, Winder AT, Liang Z, Antinori L, et al. Time to wake up: Studying neurovascular coupling and brain-wide circuit function in the un-anesthetized animal. Neuroimage. 2017;153:382-98. doi: 10.1016/j.neuroimage.2016.11.069. PubMed PMID: 27908788; PubMed Central PMCID: PMCPMC5526447.

96. Drew PJ, Winder AT, Zhang Q. Twitches, Blinks, and Fidgets: Important Generators of Ongoing Neural Activity. Neuroscientist. 2019;25(4):298-313. doi: 10.1177/1073858418805427. PubMed PMID: 30311838.

97. Stringer C, Pachitariu M, Steinmetz N, Reddy CB, Carandini M, Harris KD. Spontaneous behaviors drive multidimensional, brainwide activity. Science. 2019;364(6437):255. doi: 10.1126/science.aav7893. PubMed PMID: 31000656; PubMed Central PMCID: PMCPMC6525101.

98. Musall S, Kaufman MT, Juavinett AL, Gluf S, Churchland AK. Single-trial neural dynamics are dominated by richly varied movements. Nat Neurosci. 2019;22(10):1677-86. doi: 10.1038/s41593-019-0502-4. PubMed PMID: 31551604; PubMed Central PMCID: PMCPMC6768091.

99. Chapin JK, Woodward DJ. Modulation of sensory responsiveness of single somatosensory cortical cells during movement and arousal behaviors. Exp Neurol. 1981;72(1):164-78. PubMed PMID: 7202621.

100. Gao YR, Greene SE, Drew PJ. Mechanical restriction of intracortical vessel dilation by brain tissue sculpts the hemodynamic response. Neuroimage. 2015;115:162-76. doi: 10.1016/j.neuroimage.2015.04.054. PubMed PMID: 25953632; PubMed Central PMCID: PMCPMC4470397.

101. Huo BX, Greene SE, Drew PJ. Venous cerebral blood volume increase during voluntary locomotion reflects cardiovascular changes. Neuroimage. 2015;118:301-12. doi: 10.1016/j.neuroimage.2015.06.011. PubMed PMID: 26057593; PubMed Central PMCID: PMCPMC4555186.

102. Adams MD, Winder AT, Blinder P, Drew PJ. The pial vasculature of the mouse develops according to a sensory-independent program. Scientific Reports. 2018;8(1). doi:

10.1038/s41598-018-27910-3.

103. Mitra PP, Pesaran B. Analysis of dynamic brain imaging data. Biophys J. 1999;76(2):691-708. doi: 10.1016/S0006-3495(99)77236-X. PubMed PMID: 9929474; PubMed Central PMCID: PMCPMC1300074.

104. Gustafsson $\mathrm{H}$, Bulow A, Nilsson $\mathrm{H}$. Rhythmic contractions of isolated, pressurized small arteries from rat. Acta Physiol Scand. 1994;152(2):145-52. doi: 10.1111/j.17481716.1994.tb09794.x. PubMed PMID: 7839859.

105. Duling BR, Gore RW, Dacey RG, Jr., Damon DN. Methods for isolation, cannulation, and in vitro study of single microvessels. Am J Physiol. 1981;241(1):H108-16. doi:

10.1152/ajpheart.1981.241.1.H108. PubMed PMID: 7195654.

106. Osol G, Halpern W. Spontaneous vasomotion in pressurized cerebral arteries from genetically hypertensive rats. Am J Physiol. 1988;254(1 Pt 2):H28-33. doi:

10.1152/ajpheart.1988.254.1.H28. PubMed PMID: 3337256. 
1025

1026

1027

1028

1029

1030

1031

1032

1033

1034

1035

1036

1037

1038

1039

1040

1041

1042

1043

1044

1045

1046

1047

1048

1049

1050

1051

1052

1053

1054

1055

1056

1057

1058

1059

1060

1061

1062

1063

1064

1065

1066

1067

1068

1069

1070

1071

1072

1073

1074

1075

107. Slaaf DW, Tangelder GJ, Teirlinck HC, Reneman RS. Arteriolar vasomotion and arterial pressure reduction in rabbit tenuissimus muscle. Microvasc Res. 1987;33(1):71-80. doi: 10.1016/0026-2862(87)90008-2. PubMed PMID: 3561269.

108. Zarahn E, Aguirre GK, D'Esposito M. Empirical analyses of BOLD fMRI statistics. I. Spatially unsmoothed data collected under null-hypothesis conditions. Neuroimage. 1997;5(3):179-97. PubMed PMID: 9345548.

109. Clauset A, Shalizi CR, Newman MEJ. Power-Law Distributions in Empirical Data. SIAM Review. 2009;51(4):661-703.

110. Tsai PS, Kaufhold JP, Blinder P, Friedman B, Drew PJ, Karten HJ, et al. Correlations of neuronal and microvascular densities in murine cortex revealed by direct counting and colocalization of nuclei and vessels. J Neurosci. 2009;29(46):14553-70. doi:

10.1523/JNEUROSCI.3287-09.2009. PubMed PMID: 19923289; PubMed Central PMCID: PMCPMC4972024.

111. Blinder P, Tsai PS, Kaufhold JP, Knutsen PM, Suhl H, Kleinfeld D. The cortical angiome: an interconnected vascular network with noncolumnar patterns of blood flow. Nat Neurosci. 2013;16(7):889-97. doi: 10.1038/nn.3426. PubMed PMID: 23749145; PubMed Central PMCID: PMCPMC4141079.

112. Kirst C, Skriabine S, Vieites-Prado A, Topilko T, Bertin P, Gerschenfeld G, et al. Mapping the Fine-Scale Organization and Plasticity of the Brain Vasculature. Cell. 2020. doi: 10.1016/j.cell.2020.01.028. PubMed PMID: 32059781.

113. Goense JBM, Logothetis NK. Neurophysiology of the BOLD fMRI signal in awake monkeys. Current biology : CB. 2008;18(9):631-40.

114. Drew PJ, Duyn JH, Golanov E, Kleinfeld D. Finding coherence in spontaneous oscillations. Nat Neurosci. 2008;11(9):991-3. doi: 10.1038/nn0908-991. PubMed PMID: 18725901.

115. Shmuel A, Leopold DA. Neuronal correlates of spontaneous fluctuations in fMRI signals in monkey visual cortex: Implications for functional connectivity at rest. Hum Brain Mapp. 2008;29(7):751-61. doi: 10.1002/hbm.20580. PubMed PMID: 18465799.

116. Cohen MS. Parametric analysis of $\mathrm{FMRI}$ data using linear systems methods. Neuroimage. 1997;6(2):93-103. doi: 10.1006/nimg.1997.0278. PubMed PMID: 9299383. 117. Madsen MT. A simplified formulation of the gamma variate function. Physics in Medicine and Biology. 1992;37(7):1597-600.

118. Yu X, Qian C, Chen DY, Dodd SJ, Koretsky AP. Deciphering laminar-specific neural inputs with line-scanning fMRI. Nat Methods. 2014;11(1):55-8. doi: 10.1038/nmeth.2730. PubMed PMID: 24240320; PubMed Central PMCID: PMCPMC4276040.

119. Lindquist MA, Meng Loh J, Atlas LY, Wager TD. Modeling the hemodynamic response function in fMRI: efficiency, bias and mis-modeling. Neuroimage. 2009;45(1 Suppl):S187-98. doi: 10.1016/j.neuroimage.2008.10.065. PubMed PMID: 19084070; PubMed Central PMCID: PMCPMC3318970.

120. Gagnon L, Sakadzic S, Lesage F, Musacchia JJ, Lefebvre J, Fang Q, et al. Quantifying the microvascular origin of BOLD-fMRI from first principles with two-photon microscopy and an oxygen-sensitive nanoprobe. J Neurosci. 2015;35(8):3663-75. doi: 10.1523/JNEUROSCI.355514.2015. PubMed PMID: 25716864; PubMed Central PMCID: PMCPMC4339366.

121. Sencan I, Esipova T, Kilic K, Li B, Desjardins M, Yaseen MA, et al. Optical measurement of microvascular oxygenation and blood flow responses in awake mouse cortex during functional activation. J Cereb Blood Flow Metab. 2020:271678X20928011. doi:

10.1177/0271678X20928011. PubMed PMID: 32515672.

122. He Y, Wang M, Chen X, Pohmann R, Polimeni JR, Scheffler K, et al. Ultra-Slow SingleVessel BOLD and CBV-Based fMRI Spatiotemporal Dynamics and Their Correlation with Neuronal Intracellular Calcium Signals. Neuron. 2018;97(4):925-39 e5. doi: 10.1016/j.neuron.2018.01.025. PubMed PMID: 29398359. 
1076

1077

1078

1079

1080

1081

1082

1083

1084

1085

1086

1087

1088

1089

1090

1091

1092

1093

1094

1095

1096

1097

1098

1099

1100

1101

1102

1103

1104

1105

1106

1107

1108

1109

1110

1111

1112

1113

1114

1115

1116

1117

1118

1119

1120

1121

1122

1123

1124

1125

123. Tian P, Teng IC, May LD, Kurz R, Lu K, Scadeng M, et al. Cortical depth-specific microvascular dilation underlies laminar differences in blood oxygenation level-dependent functional MRI signal. Proc Natl Acad Sci U S A. 2010;107(34):15246-51. doi:

10.1073/pnas.1006735107. PubMed PMID: 20696904; PubMed Central PMCID: PMCPMC2930564.

124. Goense JB, Logothetis NK. Neurophysiology of the BOLD fMRI signal in awake monkeys. Curr Biol. 2008;18(9):631-40. doi: 10.1016/j.cub.2008.03.054. PubMed PMID: 18439825.

125. Vazquez AL, Noll DC. Nonlinear aspects of the BOLD response in functional MRI. Neuroimage. 1998;7(2):108-18. doi: 10.1006/nimg.1997.0316. PubMed PMID: 9558643. 126. Chen JE, Lewis LD, Chang C, Tian Q, Fultz NE, Ohringer NA, et al. Resting-state "physiological networks". Neuroimage. 2020;213:116707. doi:

10.1016/j.neuroimage.2020.116707. PubMed PMID: 32145437; PubMed Central PMCID: PMCPMC7165049.

127. Peng CK, Mietus JE, Liu Y, Lee C, Hausdorff JM, Stanley HE, et al. Quantifying fractal dynamics of human respiration: age and gender effects. Ann Biomed Eng. 2002;30(5):683-92. doi: 10.1114/1.1481053. PubMed PMID: 12108842.

128. Erdener ŞE, Tang J, Sajjadi A, Kılıç K, Kura S, Schaffer CB, et al. Spatio-temporal dynamics of cerebral capillary segments with stalling red blood cells. Journal of Cerebral Blood Flow \& Metabolism. 2017;39(5):886-900. doi: 10.1177/0271678x17743877.

129. Forouzan O, Yang X, Sosa JM, Burns JM, Shevkoplyas SS. Spontaneous oscillations of capillary blood flow in artificial microvascular networks. Microvasc Res. 2012;84(2):123-32. doi: 10.1016/j.mvr.2012.06.006. PubMed PMID: 22732344.

130. Kaulakys B, Meškauskas T. Modeling1/fnoise. Physical Review E. 1998;58(6):7013-9. doi: 10.1103/PhysRevE.58.7013.

131. Shih AY, Driscoll JD, Drew PJ, Nishimura N, Schaffer CB, Kleinfeld D. Two-photon microscopy as a tool to study blood flow and neurovascular coupling in the rodent brain. J Cereb Blood Flow Metab. 2012;32(7):1277-309. doi: 10.1038/jcbfm.2011.196. PubMed PMID: 22293983; PubMed Central PMCID: PMCPMC3390800.

132. Lecoq J, Tiret P, Najac M, Shepherd GM, Greer CA, Charpak S. Odor-evoked oxygen consumption by action potential and synaptic transmission in the olfactory bulb. J Neurosci. 2009;29(5):1424-33. doi: 10.1523/JNEUROSCI.4817-08.2009. PubMed PMID: 19193889; PubMed Central PMCID: PMCPMC2662132.

133. Cybulski O, Garstecki P, Grzybowski BA. Oscillating droplet trains in microfluidic networks and their suppression in blood flow. Nature Physics. 2019;15(7):706-13. doi:

10.1038/s41567-019-0486-8.

134. Aon MA, Cortassa S, O'Rourke B. The fundamental organization of cardiac mitochondria as a network of coupled oscillators. Biophys J. 2006;91(11):4317-27. doi:

10.1529/biophysj.106.087817. PubMed PMID: 16980364; PubMed Central PMCID: PMCPMC1635654.

135. Kurz FT, Derungs T, Aon MA, O'Rourke B, Armoundas AA. Mitochondrial networks in cardiac myocytes reveal dynamic coupling behavior. Biophys J. 2015;108(8):1922-33. doi:

10.1016/j.bpj.2015.01.040. PubMed PMID: 25902432; PubMed Central PMCID: PMCPMC4407245.

136. Porat-Shliom N, Chen Y, Tora M, Shitara A, Masedunskas A, Weigert R. In vivo tissuewide synchronization of mitochondrial metabolic oscillations. Cell Rep. 2014;9(2):514-21. doi: 10.1016/j.celrep.2014.09.022. PubMed PMID: 25373899; PubMed Central PMCID: PMCPMC4223640.

137. Aon MA, Roussel MR, Cortassa S, O'Rourke B, Murray DB, Beckmann M, et al. The scale-free dynamics of eukaryotic cells. PLoS One. 2008;3(11):e3624. doi: 
10.1371/journal.pone.0003624. PubMed PMID: 18982073; PubMed Central PMCID: PMCPMC2575856.

138. Chaui-Berlinck JG, Bicudo JEPW, Monteiro LHA, Navas CA. Oscillatory pattern in oxygen consumption of Hummingbirds. Journal of Thermal Biology. 2002;27(5):371-9. doi: 10.1016/s0306-4565(02)00005-0.

139. Vern BA, Schuette WH, Leheta B, Juel VC, Radulovacki M. Low-frequency oscillations of cortical oxidative metabolism in waking and sleep. J Cereb Blood Flow Metab. 1988;8(2):21526. doi: 10.1038/jcbfm.1988.52. PubMed PMID: 2830291.

140. Hall CN, Klein-Flugge MC, Howarth C, Attwell D. Oxidative phosphorylation, not glycolysis, powers presynaptic and postsynaptic mechanisms underlying brain information processing. J Neurosci. 2012;32(26):8940-51. doi: 10.1523/JNEUROSCI.0026-12.2012. PubMed PMID: 22745494; PubMed Central PMCID: PMCPMC3390246.

141. Schmid F, Reichold J, Weber B, Jenny P. The impact of capillary dilation on the distribution of red blood cells in artificial networks. Am J Physiol Heart Circ Physiol.

2015;308(7):H733-42. doi: 10.1152/ajpheart.00335.2014. PubMed PMID: 25617356.

142. Herman P, Eke A. Nonlinear analysis of blood cell flux fluctuations in the rat brain cortex during stepwise hypotension challenge. J Cereb Blood Flow Metab. 2006;26(9):1189-97. doi: 10.1038/sj.jcbfm.9600266. PubMed PMID: 16395288.

143. Kiani MF, Pries AR, Hsu LL, Sarelius IH, Cokelet GR. Fluctuations in microvascular blood flow parameters caused by hemodynamic mechanisms. Am J Physiol. 1994;266(5 Pt 2):H1822-8. doi: 10.1152/ajpheart.1994.266.5.H1822. PubMed PMID: 8203581.

144. Hall CN, Reynell C, Gesslein B, Hamilton NB, Mishra A, Sutherland BA, et al. Capillary pericytes regulate cerebral blood flow in health and disease. Nature. 2014;508(7494):55-60. doi: 10.1038/nature13165. PubMed PMID: 24670647; PubMed Central PMCID: PMCPMC3976267. 145. Mishra A, Reynolds JP, Chen Y, Gourine AV, Rusakov DA, Attwell D. Astrocytes mediate neurovascular signaling to capillary pericytes but not to arterioles. Nat Neurosci. 2016;19(12):1619-27. doi: 10.1038/nn.4428. PubMed PMID: 27775719; PubMed Central PMCID: PMCPMC5131849.

146. Rungta RL, Chaigneau E, Osmanski BF, Charpak S. Vascular Compartmentalization of Functional Hyperemia from the Synapse to the Pia. Neuron. 2018;99(2):362-75 e4. doi: 10.1016/j.neuron.2018.06.012. PubMed PMID: 29937277; PubMed Central PMCID: PMCPMC6069674.

147. Zhang R, Zuckerman JH, Levine BD. Spontaneous fluctuations in cerebral blood flow: insights from extended-duration recordings in humans. Am J Physiol Heart Circ Physiol. 2000;278(6):H1848-55. doi: 10.1152/ajpheart.2000.278.6.H1848. PubMed PMID: 10843881. 148. Silverman DA, Rakusan K. Red blood cell spacing in rat coronary capillaries during the cardiac cycle. Microvasc Res. 1996;52(2):143-56. doi: 10.1006/mvre.1996.0050. PubMed PMID: 8901443.

149. Pradhan RK, Chakravarthy VS, Prabhakar A. Effect of chaotic vasomotion in skeletal muscle on tissue oxygenation. Microvasc Res. 2007;74(1):51-64. doi:

10.1016/j.mvr.2007.02.004. PubMed PMID: 17418241.

150. Kisler K, Nelson AR, Rege SV, Ramanathan A, Wang Y, Ahuja A, et al. Pericyte degeneration leads to neurovascular uncoupling and limits oxygen supply to brain. Nat Neurosci. 2017;20(3):406-16. doi: 10.1038/nn.4489. PubMed PMID: 28135240; PubMed Central PMCID: PMCPMC5323291.

151. Hill RA, Tong L, Yuan P, Murikinati S, Gupta S, Grutzendler J. Regional Blood Flow in the Normal and Ischemic Brain Is Controlled by Arteriolar Smooth Muscle Cell Contractility and Not by Capillary Pericytes. Neuron. 2015;87(1):95-110. doi: 10.1016/j.neuron.2015.06.001. PubMed PMID: 26119027; PubMed Central PMCID: PMCPMC4487786. 
152. Drew PJ, Shih AY, Driscoll JD, Knutsen PM, Blinder P, Davalos D, et al. Chronic optical access through a polished and reinforced thinned skull. Nat Methods. 2010;7(12):981-4. doi: 10.1038/nmeth.1530. PubMed PMID: 20966916; PubMed Central PMCID: PMCPMC3204312. 153. Shirey MJ, Smith JB, Kudlik DE, Huo BX, Greene SE, Drew PJ. Brief anesthesia, but not voluntary locomotion, significantly alters cortical temperature. J Neurophysiol. 2015;114(1):30922. doi: 10.1152/jn.00046.2015. PubMed PMID: 25972579; PubMed Central PMCID: PMCPMC4507947.

154. Gao YR, Drew PJ. Effects of Voluntary Locomotion and Calcitonin Gene-Related Peptide on the Dynamics of Single Dural Vessels in Awake Mice. J Neurosci. 2016;36(8):250316. doi: 10.1523/JNEUROSCI.3665-15.2016. PubMed PMID: 26911696; PubMed Central PMCID: PMCPMC4764666.

155. Jenkins GM, Watts DG. Spectral analysis and its applications. San Francisco,: HoldenDay; 1968. xviii, 525 p. p.

156. Boynton GM, Engel SA, Glover GH, Heeger DJ. Linear systems analysis of functional magnetic resonance imaging in human V1. J Neurosci. 1996;16(13):4207-21. PubMed PMID: 8753882.

157. Glover GH. Deconvolution of impulse response in event-related BOLD fMRI. Neuroimage. 1999;9(4):416-29. PubMed PMID: 10191170.

158. Lamkin-Kennard KA, Buerk DG, Jaron D. Interactions between NO and $\mathrm{O} 2$ in the microcirculation: a mathematical analysis. Microvasc Res. 2004;68(1):38-50. doi:

10.1016/j.mvr.2004.03.001. PubMed PMID: 15219419.

159. Sakadzic S, Yaseen MA, Jaswal R, Roussakis E, Dale AM, Buxton RB, et al. Twophoton microscopy measurement of cerebral metabolic rate of oxygen using periarteriolar oxygen concentration gradients. Neurophotonics. 2016;3(4):045005. doi:

10.1117/1.NPh.3.4.045005. PubMed PMID: 27774493; PubMed Central PMCID: PMCPMC5066455.

160. Ni R, Rudin M, Klohs J. Cortical hypoperfusion and reduced cerebral metabolic rate of oxygen in the arcAbeta mouse model of Alzheimer's disease. Photoacoustics. 2018;10:38-47. doi: 10.1016/j.pacs.2018.04.001. PubMed PMID: 29682448; PubMed Central PMCID: PMCPMC5909030.

161. Helgason H, Pipiras V, Abry P. Synthesis of multivariate stationary series with prescribed marginal distributions and covariance using circulant matrix embedding. Signal Processing. 2011;91(8):1741-58. doi: 10.1016/j.sigpro.2011.01.020.

162. He BJ. Scale-free brain activity: past, present, and future. Trends Cogn Sci. 2014;18(9):480-7. doi: 10.1016/j.tics.2014.04.003. PubMed PMID: 24788139; PubMed Central PMCID: PMCPMC4149861.

163. Touboul J, Destexhe A. Power-law statistics and universal scaling in the absence of criticality. Phys Rev E. 2017;95(1-1):012413. doi: 10.1103/PhysRevE.95.012413. PubMed PMID: 28208383.

164. Ton R, Daffertshofer A. Model selection for identifying power-law scaling. Neuroimage. 2016;136:215-26. doi: 10.1016/j.neuroimage.2016.01.008. PubMed PMID: 26774613.

165. Wen H, Liu Z. Separating Fractal and Oscillatory Components in the Power Spectrum of Neurophysiological Signal. Brain Topogr. 2016;29(1):13-26. doi: 10.1007/s10548-015-0448-0. PubMed PMID: 26318848; PubMed Central PMCID: PMCPMC4706469.

166. Yamamoto $\mathrm{Y}$, Hughson RL. Coarse-graining spectral analysis: new method for studying heart rate variability. J Appl Physiol (1985). 1991;71(3):1143-50. PubMed PMID: 1757311.

167. Ma Y, Shaik MA, Kozberg MG, Kim SH, Portes JP, Timerman D, et al. Resting-state hemodynamics are spatiotemporally coupled to synchronized and symmetric neural activity in excitatory neurons. Proc Natl Acad Sci U S A. 2016;113(52):E8463-E71. doi: 10.1073/pnas.1525369113. PubMed PMID: 27974609; PubMed Central PMCID: PMCPMC5206542. 
bioRxiv preprint doi: https://doi.org/10.1101/2020.09.18.303164; this version posted September 20, 2020. The copyright holder for this preprint (which was not certified by peer review) is the author/funder. All rights reserved. No reuse allowed without permission.

1226 168. Baranauskas G, Maggiolini E, Vato A, Angotzi G, Bonfanti A, Zambra G, et al. Origins of 1227 1/f2 scaling in the power spectrum of intracortical local field potential. J Neurophysiol.

1228 2012;107(3):984-94. doi: 10.1152/jn.00470.2011. PubMed PMID: 22090461.

1229 
1231 Figure 1. Illustration of white noise, periodic and 1/f-like signal. (a) An example of white noise 1232 (left) and its power spectrum (right). The solid black line denotes the linear regression fit. (b) An 1233 example of a periodic signal with peak frequency centered at $0.2 \mathrm{~Hz}$ (left) and its power spectrum 1234 (right). (c) An example of fractional Gaussian noise (i.e., 1/f-like) with Hurst exponent $=0.9$ (left) and its power spectrum (right). (d) An example of additive signal combining fractional Gaussian noise and periodic signal (left) and its power spectrum (right).

1237 Figure 2. 1/f-like dynamics of tissue oxygenation. (a) Experimental setup (top) and a summary of measurement sites (bottom). (b) Example trace showing the spontaneous fluctuations of tissue oxygenation $\left(\mathrm{PtO}_{2}\right) 300 \mu \mathrm{m}$ below the pia. (c) Power spectrum of the $\mathrm{PtO}_{2}$ (solid line) as well as its power-law fit (dashed line) using data from resting period (orange) and periods including both rest and locomotion (green). The residual power (i.e., the difference between the power spectrum of the observed oxygen signal and the power-law fit) is shown in the bottom. (d) The power spectrum of $\mathrm{PtO}_{2}$ (purple) and its linear regression fit (black) from a dead mouse. (e) Group average of power spectrum during periods of rest (solid line) and periods including both rest and locomotion (dashed line) across different cortical depths in both FL/HL $(n=23$ mice) and FC ( $n=$ 14 mice). (f) Group average of power-law exponent across different cortical layers during periods of rest (top) and periods including both rest and locomotion (bottom). Blue circles denote the measurements in FL/HL while the magenta circles denote the measurements in FC. (g) Scatter plot showing the increase of power-law exponent during periods including locomotion. The orange line indicates the unity line. Data are shown as mean \pm SEM in (e) and (f).

1251 Figure 3. 1/f-like dynamics of BLP signals for gamma-band. (a) Experimental setup. Top, 1252 schematic showing all laminar electrophysiology measurement sites in FC ( $n=3$ mice) and FL/HL 1253 ( $n=6$ mice). Bottom, schematic showing the layout of the electrodes and measurement depth.

1254 (b) Schematic outline the general method creating the BLP signals. Raw LFP data was first band1255 pass filtered and then rectified. The resulting signal was then low pass filtered and resampled. 1256 This procedure was applied to each LFP signal for three different frequency ranges. (c) Example 1257 tracing showing the application of this scheme to one LFP signals, for the gamma-band frequency 1258 range. (d) Power spectrum of Gamma-band LFP power across cortical depth during rest (left) and 1259 periods including rest and locomotion (right). The dashed lines denote the linear regression fit. 1260 Data are shown as mean \pm SEM.

1261 Figure 4. Weak coherence between BLP and tissue oxygenation. Magnitude-squared 1262 coherence between gamma-band LFP power (a), beta-band LFP power (b), sub-alpha band LFP 
1263 power (c), respiratory rate (d) and tissue oxygenation during rest. The orange line denotes the

$126495 \%$ confidence interval of the coherence. Data are shown as mean \pm SEM.

1265 Figure 5. Non-neuronal factors contribute to the $1 /$ f-like dynamics of tissue oxygenation.

1266 (a) Experimental setup. (b) Group average of the hemodynamic response function (HRF) 1267 obtained by deconvolving brain tissue oxygenation by gamma-band power of the LFP. Data are 1268 shown as mean \pm SEM. (c) Power spectrum of actual (black) and predicted (red) oxygenation. 1269 Data are shown as mean \pm SEM. (d) Power-law exponent of actual (black) and predicted (red) oxygenation in FL/HL (4 mice, black circle) and FC (5 mice, orange circle). Data are shown as mean \pm SD. * paired t-test, $t(8)=3.2520, p=0.0117$.

1272 Figure 6. 1/f-like fluctuations persist when neural activity is suppressed. (a) Experimental setup. (b) Example traces showing $\mathrm{PtO}_{2}$ responses to locomotion at sites $170 \mu \mathrm{m}$ below brain surface before (left) and after (right) CNQX/AP5/muscimol. Top, black ticks denote locomotion events; middle, $\mathrm{PtO}_{2}$ (black) and respiratory rate (orange) responses to locomotion; bottom, example of data showing spectrogram of LFP (cyan trace showing the gamma-band power). (c) Comparison of resting gamma-band power of LFP and $\mathrm{PtO}_{2}$ fluctuations quantified with the standard deviation of the signal. Black circles and bars outside the axes show the population mean and SD. The dashed gray line is the unity line. Clustering of the points in the upper left corner shows a pronounced decrease in the neural activity was not accompanied by a decrease in the amplitude of the oxygen fluctuations. (d) Power spectrum of tissue oxygen signal before (black) and after (red) application of CNQX/AP5/muscimol using resting data (left) and data including both rest and locomotion (right). (e) Power-law exponent of tissue oxygen signal before (black) and after (red) application of CNQX/AP5/muscimol using resting data (left) and data including both rest and locomotion (right).

Figure 7. RBCs spacing heterogeneity contributes to $1 /$ f-like oxygen fluctuations. (a)

1287 Example line scan images showing the RBCs spacing in two different capillaries with (top) and 1288 without (bottom) stall events in an example mouse during rest. The images on the left showing 1289 the vasculature around the measurement sites, as indicated by the magenta line. Scale bar $=50$ $1290 \mu \mathrm{m}$. The magenta dots indicate the detected RBCs locations. (b) Left, lagged scatter plot showing 1291 the relationship between consecutive RBC spacing intervals (i.e., autocorrelation trend) of 1292 capillary \#1. The dark area indicates the density of the RBC spacing. Right, power spectrum for 1293 the RBC spacing of capillary \#1. The scatter plot showing 3341 RBCs in a 142.8 second resting 1294 period. (c) As (b) but for capillary \#2. The scatter plot showing 2603 RBCs in a 100.4 second 1295 resting period. (d) Power spectrum of inter-RBC transit time for data without stall events (black) 
1296 and with stall events (red). Inset, fitted power-law exponent for each of the capillaries with (red 1297 circle) and without (black circle) stall events. (e) Schematic showing that $\mathrm{PO}_{2}$ measured at the 1298 RBC border decreases with distance and reaches its lowest value between two RBCs. Orange 1299 line inside the capillary denotes the oxygenation carried by the RBC and the diffusion to plasma 1300 due to intravascular resistance. The gray shaded area denotes brain tissue. Solid traces inside 1301 the gray shaded area denotes $\mathrm{PtO}_{2}$ at different distance away from the capillary wall (as indicated 1302 by the arrow). (f) Simulated data showing the fluctuations of RBC spacing (top), oxygenation in 1303 the capillary (middle) and oxygen in the tissue (bottom) generated by simulating a Krogh cylinder 1304 of $20 \mu \mathrm{m}$ radius supplied by a capillary of $3 \mu \mathrm{m}$ radius. The orange box denotes a 1 second 1305 segment of the dataset. The red tick marks denote the passage of a single RBC. (g) Lagged 1306 scatter plot showing the relationship between consecutive RBC spacing intervals for a segment 1307 ( 3000 RBCs interval) of the simulated data shown in (f). (h) Comparison of power spectrum of 1308 tissue oxygenation measured using polarographic electrodes (black) and generated using the 1309 simple model (red) as shown in (g). Shaded area denotes 1 SEM. 


\section{Supplementary figures}

1311 Supplementary Figure 1. Compare raw spectral power of brain tissue oxygen at rest and 1312 including locomotion. Related to Figure 2e.

1313 Supplementary Figure 2. 1/f-like power spectra of broadband LFPs and spike rate. (a) 1314 Experimental setup. Top, schematic showing all laminar electrophysiology measurement sites in $1315 \mathrm{FC}(\mathrm{n}=3$ mice) and FL/HL ( $=6$ mice). Bottom, schematic showing the layout of the electrodes 1316 and measurement depth. (b) An example trace showing the broad-band LFP at different cortical 1317 depths in the FL/HL. (c) An example trace showing the MUA at different cortical depths in the $1318 \mathrm{FL} / \mathrm{HL}$ in the same trial as (b). (d) Top, power spectrum of broadband (1-100 Hz) LFP across 1319 cortical depth during rest and periods including rest and locomotion. Bottom, power-law fit exponent. For all cortical layers, the power spectrum showed $1 / \mathrm{f}$-like behavior over $5 \mathrm{~Hz}$, so we fit the power spectrum between $5-100 \mathrm{~Hz}$ at each layer with a power-law distribution to avoid the "shoulder". To compare with the above oxygen measurements, we selected LFPs from recordings $100 \mu \mathrm{m}, 300 \mu \mathrm{m}, 500 \mu \mathrm{m}$ and $800 \mu \mathrm{m}$ below the cortical surface. We found the fitted power law exponent was not significantly different across cortical depths at rest $(1.70 \pm 0.28$ at $100 \mu \mathrm{m}, 1.98$ \pm 0.33 at $300 \mu \mathrm{m}, 2.05 \pm 0.46$ at $500 \mu \mathrm{m}, 2.09 \pm 0.32$ at $800 \mu \mathrm{m} ; \mathrm{n}=6$ mice (9 sites), KruskalWallis test, $\left.\chi^{2}(3,35)=5.89, p=0.1172\right)$. Including locomotion period did not change the relationship across cortical depths $(1.71 \pm 0.25$ at $100 \mu \mathrm{m}, 1.88 \pm 0.30$ at $300 \mu \mathrm{m}, 2.00 \pm 0.47$ at $500 \mu \mathrm{m}, 2.14 \pm 0.31$ at $800 \mu \mathrm{m} ; \mathrm{n}=6$ mice (9 sites), Kruskal-Wallis test, $\chi^{2}(3,35)=7.55, \mathrm{p}=$ $0.0562)$. Compared to the resting only data, including the locomotion periods did not increase the power law exponent (average across all cortical layers for each animal, $n=6$ mice ( 9 sites), rest: $1.95 \pm 0.37$, rest and locomotion: $1.93 \pm 0.36$, paired t-test, $t(35)=0.9424, p=0.3525)$. (e) Top, power spectrum of spike train across cortical depths during rest and periods including rest and locomotion. Bottom, power-law fit exponent. In addition to the broad-band LFPs, the spiking rate of neurons is also correlated with vasodilation, increases in blood flow and blood oxygenation [25, $30,32,38,167]$. To address whether the spike rate activity also shows 1/f-like activity, we estimated power spectrum of multi-unit spike trains after minimally smoothing the spike trains with a Gaussian kernel with full-width at half maximum (FWHM) of $10 \mathrm{~ms}$. As spikes in surface layers are affected with noise, we made this comparison using the deeper layers, i.e., $500 \mu \mathrm{m}$ and 800 $\mu \mathrm{m}$ below the pia. Fitting spike train power with a power-law distribution revealed 1/f-like dynamics at rest (power-law exponent: $0.56 \pm 0.23$ at $500 \mu \mathrm{m}, 0.59 \pm 0.20$ at $800 \mu \mathrm{m}$ ). The resting power spectrum of spiking activity is much smaller compared to the broad-band LFPs (LFPs: $2.07 \pm 0.39$, MUA: $0.58 \pm 0.21$, Wilcoxon rank sum test, $p<0.0001$ ), which is consistent with study [168] 
1344 trace and says little about properties of the associated neuronal firing. Data are shown as mean $1345 \pm$ SEM in (d) and (e).

1346 Supplementary Figure 3. Band-limited power in sub-alpha and beta frequency bands are 1347 not 1/f-like. Related to Figure 3. (a) Experimental setup. (b) Power spectrum of the beta-band 1348 power of LFP at different cortical depths. Dashed line denotes the linear regression fit of the power. 1349 (c) As (b) but for subalpha-band power of LFP. Data are shown as mean \pm SEM.

1350 Supplementary Figure 4. Illustration of the deconvolution and convolution process.

1351 Related to Figure 5. To estimate how much variance of oxygenation the neural activity can predict, 1352 we first split the observed data ( 40 $\mathrm{min}$ ) into two segments with equal length. We then calculated 1353 the HRF using the first half of the observed data. To increase the signal-to-noise level of the HRF, 1354 we smoothed the HRF using a Savitzky-Golay filter ( $3^{\text {rd }}$ order, 11-point frame length). Next, we 1355 convolved the HRF with the gamma band LFP power from the second half, and estimated the 1356 oxygenation predicted by neural activity (orange line).

1357 Supplementary Figure 5. Impact of pharmacological silencing on neural dynamics. Related 1358 to Figure 6. (a) Experimental setup. (b) Power spectrum of broadband (1-100 Hz) LFP signal 1359 before (black) and after (red) application of CNQX/AP5/muscimol using data during rest (left) and 1360 using data including rest and locomotion (right). We asked if this suppression of spiking and LFP 1361 oscillations changes the 1/f-like dynamics of neural activity. When the craniotomy was superfused 1362 with aCSF, the power spectrum of raw LFP was relatively flat in the lower frequency range (below 1363 a "knee" at $5 \mathrm{~Hz}$ ), and the rest followed a form close to $P \propto 1 / f^{2}$. Application of 1364 CNQX/AP5/muscimol suppressed power at higher frequencies (5-100 Hz), but did not change the 1365 power law scaling at rest (aCSF, $2.21 \pm 0.13$; CNQX/AP5/muscimol, $2.16 \pm 0.21$; paired t-test, $\mathrm{t}(7)$ $1366=0.5437, \mathrm{p}=0.6035)$. Including locomotion period did not change the relationship (aCSF, $1.92 \pm$ 1367 0.20; CNQX/AP5/muscimol, $2.08 \pm 0.19$; paired t-test, $t(8)=1.9318, p=0.0895)$. For lower 1368 frequency band (1-5 Hz), drug application increased the power law scaling at rest (aCSF, $-0.19 \pm$ 1369 0.43; CNQX/AP5/muscimol, $1.40 \pm 0.77$; paired t-test, $\mathrm{t}(7)=9.1504, \mathrm{p}<0.0001)$. Including running 1370 period does not change the relationship (aCSF, $-0.15 \pm 0.28$; CNQX/AP5/muscimol, $1.34 \pm 0.69$; 1371 Wilcoxon rank sum test, $p<0.0001$ ). (c) Group average of fitted power-law exponent of 1372 broadband LFP. (d) Power spectrum of gamma-band power of LFP before (black) and after (red) 1373 application of CNQX/AP5/muscimol using data during rest (left) and using data including rest and 1374 locomotion (right). We calculated the frequency dependence of the band limited power 1375 fluctuations in the gamma-band of LFP during resting periods (aCSF: $0.16 \pm 0.29$; 1376 CNQX/AP5/muscimol: $0.07 \pm 0.31$, paired t-test, $t(7)=2.0729, p=0.0769$ ) and during resting and 
1377 running period (aCSF: $0.61 \pm 0.14$; CNQX/AP5/muscimol: $0.36 \pm 0.35$, Wilcoxon rank sum test, $p$ $1378=0.1903$ ), and did not observe any change in terms of power-law scaling before and after drug 1379 application. (e) Group average of power-law exponent of BLP for gamma-band.

1380 Supplementary Figure 6. Power spectrum and power law fits of respiratory rate 1381 fluctuations. (a) Power spectrum of respiratory rate fluctuations before (black) and after (red) 1382 application of CNQX/AP5/muscimol using resting data (left) and data including both rest and 1383 locomotion (right). (b) Power-law exponent of respiratory rate fluctuations before (black) and after 1384 (red) application of CNQX/AP5/muscimol using resting data (left) and data including both rest and 1385 locomotion (right).

1386 Supplementary Figure 7. Power spectrum and power law fit of respiratory rate fluctuations.

1387 Related to Figure 7. Comparison of power spectrum of tissue oxygenation measured using 1388 polarographic electrodes (black) and calculated using the simple model under different flow rate.

1389 Shaded area denotes 1 SEM.

1390 
bioRxiv preprint doi: https://doi.org/10.1101/2020.09.18.303164; this version posted September 20, 2020. The copyright holder for this preprint (which was not certified by peer review) is the author/funder. All rights reserved. No reuse allowed without permission.

Fig.1
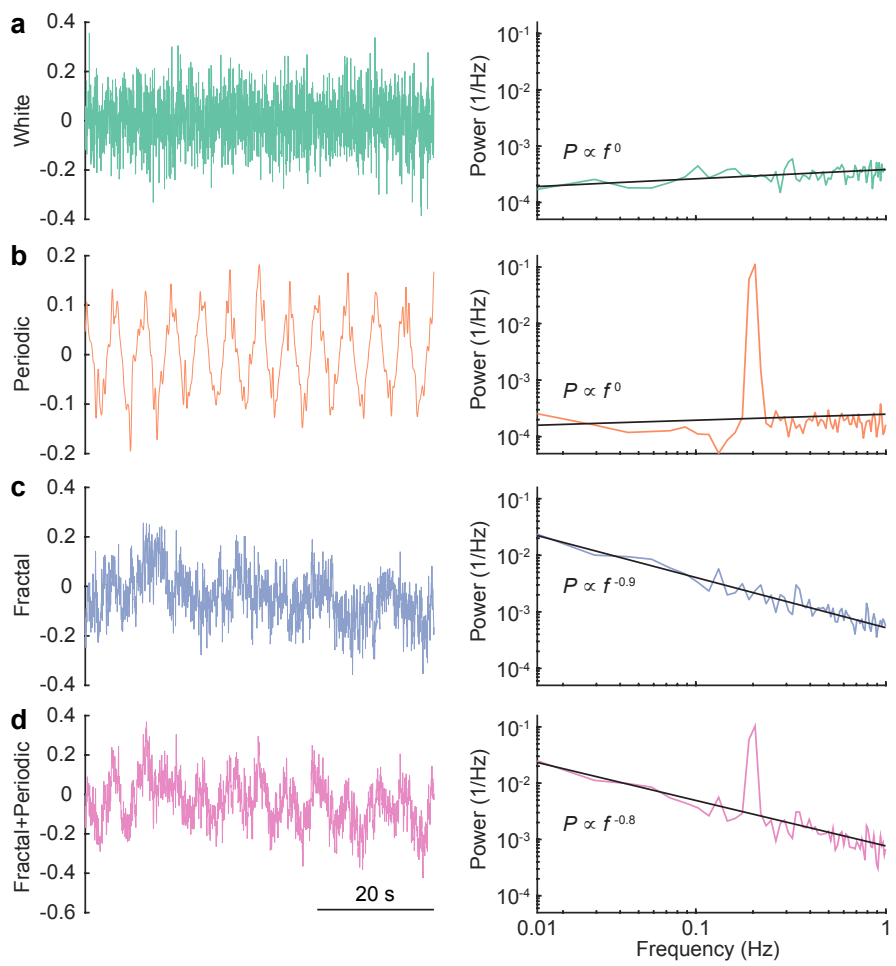
bioRxiv preprint doi: https://doi.org/10.1101/2020.09.18.303164; this version posted September 20, 2020. The copyright holder for this preprint Fig.2

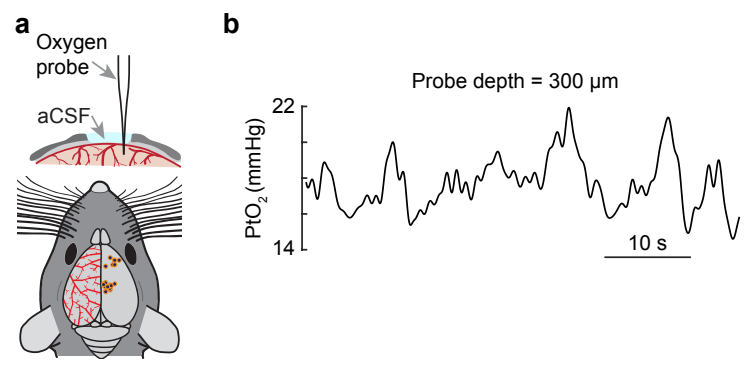

c

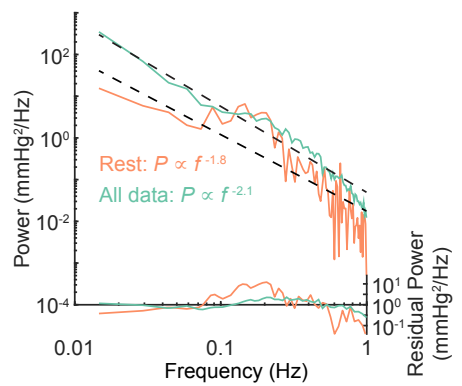

f

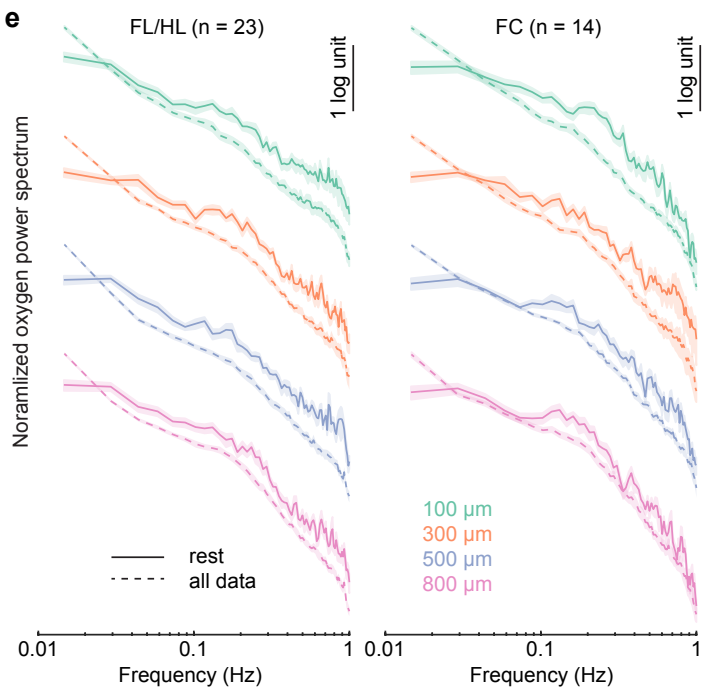

f
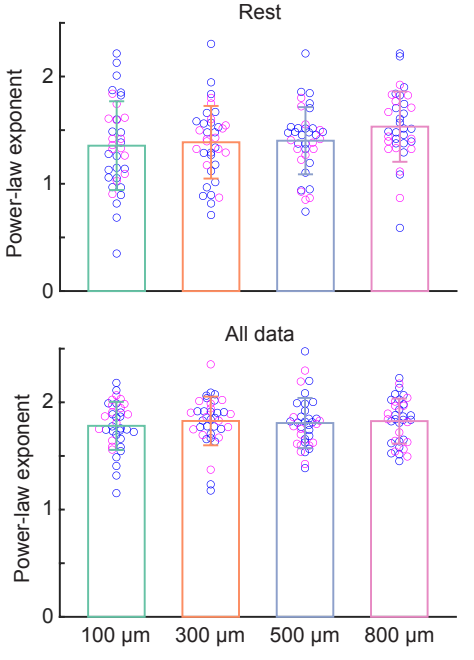

d

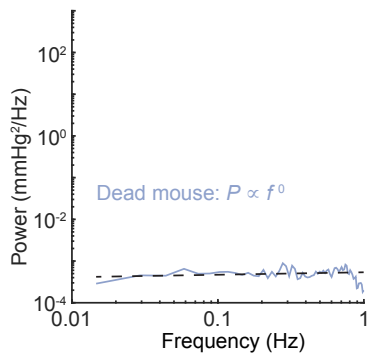

g

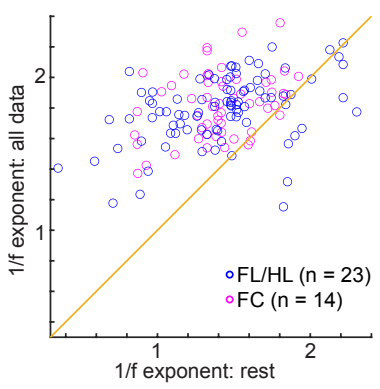


bioRxiv preprint doi: https://doi.org/10.1101/2020.09.18.303164; this version posted September 20, 2020. The copyright holder for this preprint Fig. ${ }^{\text {(wh }}$

a

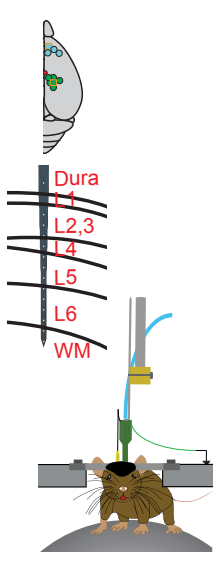

b

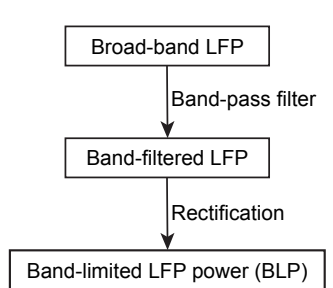

c Local field potential

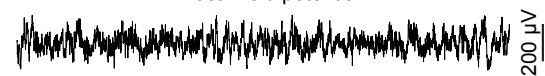

Gamma-band $(40-100 \mathrm{~Hz})$

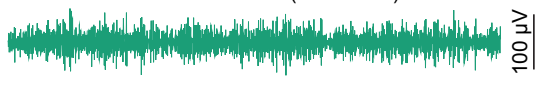

Gamma-band power

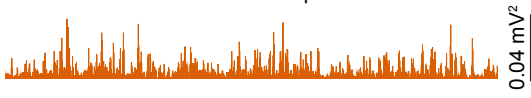

Filtered $(\leq 1 \mathrm{~Hz}$ ) gamma-band power

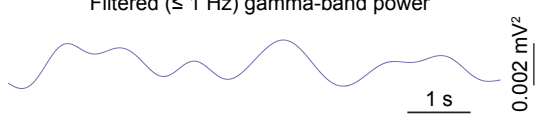

d

Rest

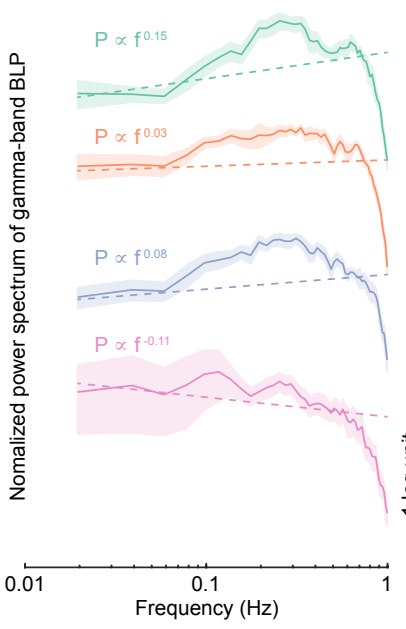

Rest and locomotion

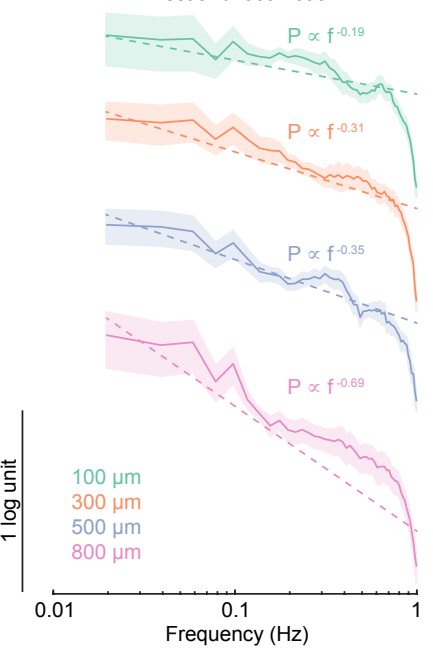


bioRxiv preprint doi: https://doi.org/10.1101/2020.09.18.303164; this version posted September 20, 2020. The copyright holder for this preprint (which was not certified by peer review) is the author/funder. All rights reserved. No reuse allowed without permission.

Fig.4
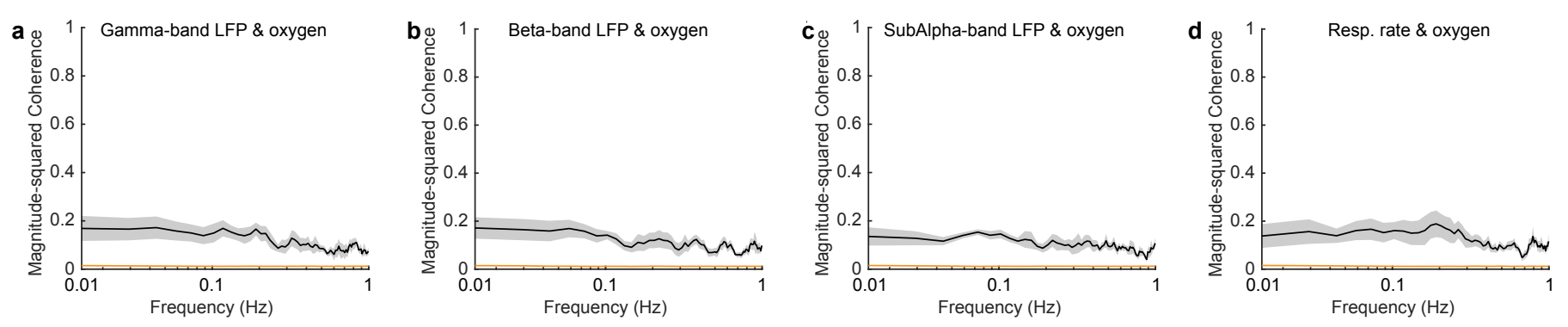
bioRxiv preprint doi: https://doi.org/10.1101/2020.09.18.303164; this version posted September 20, 2020. The copyright holder for this preprint Fig. 5

a

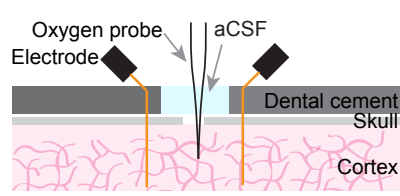

b

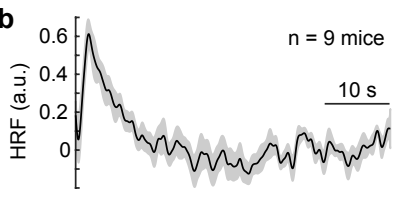

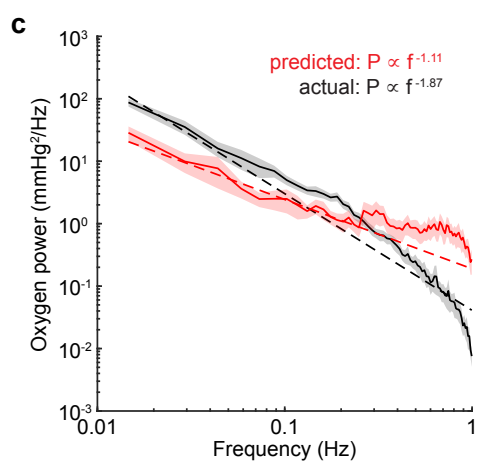

d

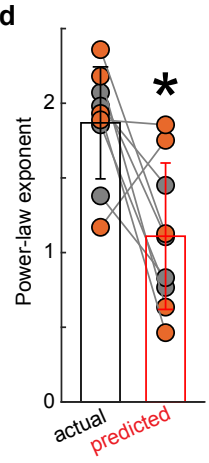


bioRxiv preprint doi: https://doi.org/10.1101/2020.09.18.303164; this version posted September 20, 2020. The copyright holder for this preprint (which was not certified by peer review) is the author/funder. All rights reserved. No reuse allowed without permission.

Fig.6

a

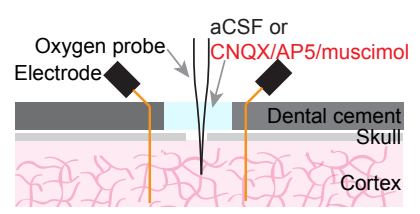

C

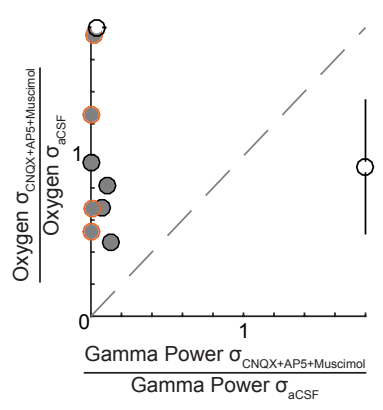

b
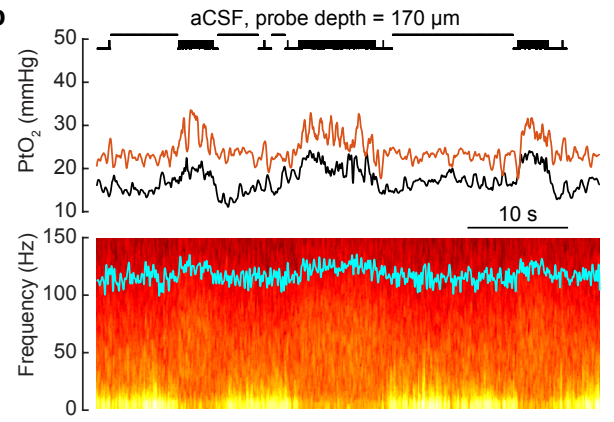

d

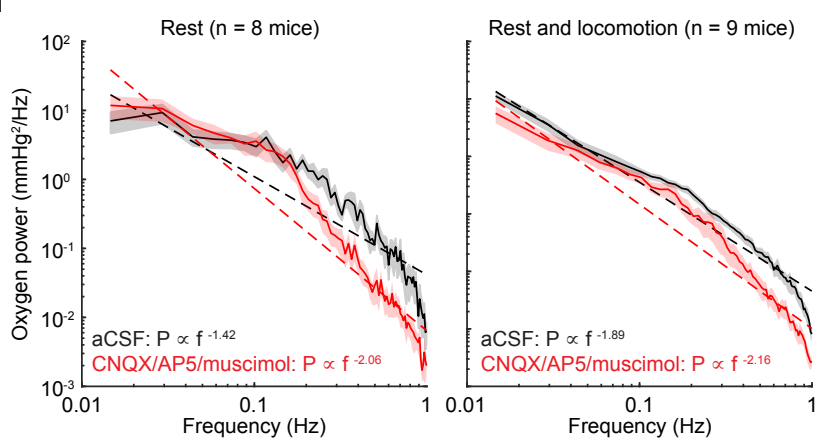

$\mathrm{CNQX/AP5/muscimol,} \mathrm{probe} \mathrm{depth}=170 \mu \mathrm{m}$
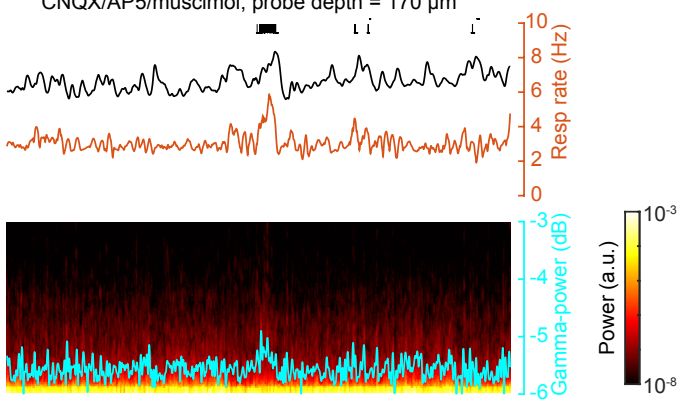

e

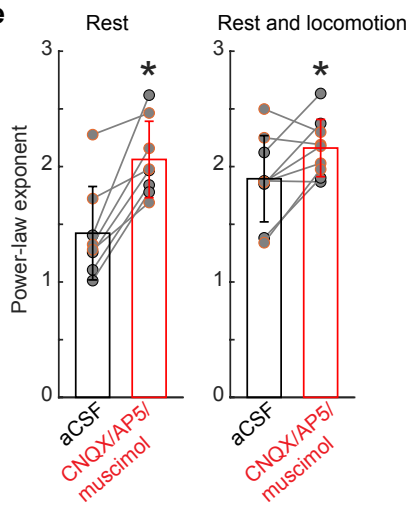


bioRxiv preprint doi: https://doi.org/10.1101/2020.09.18.303164; this version posted September 20, 2020. The copyright holder for this preprint Fig. 7

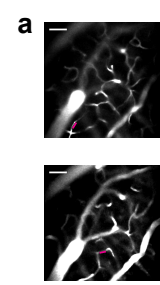

b
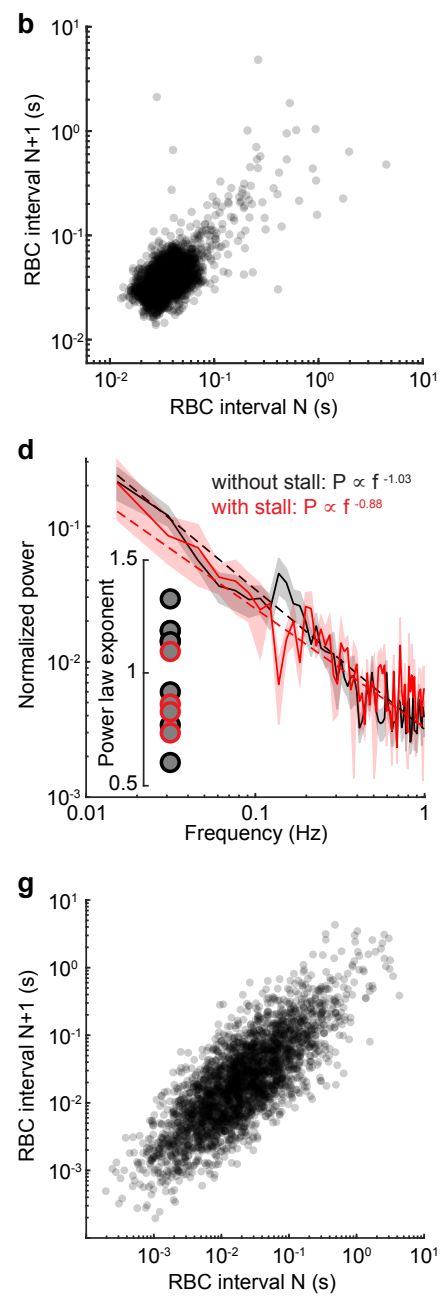

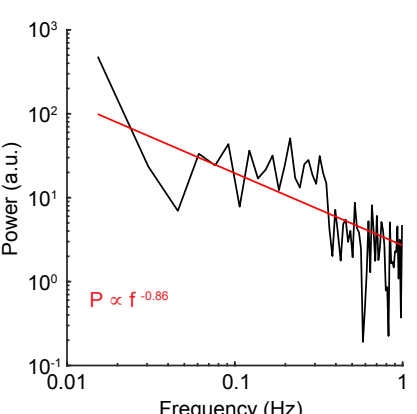

e

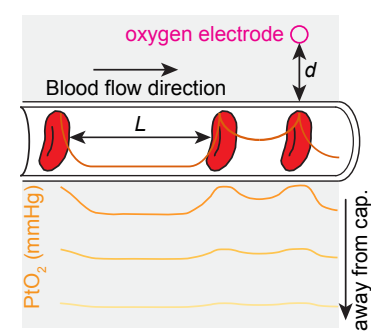

h

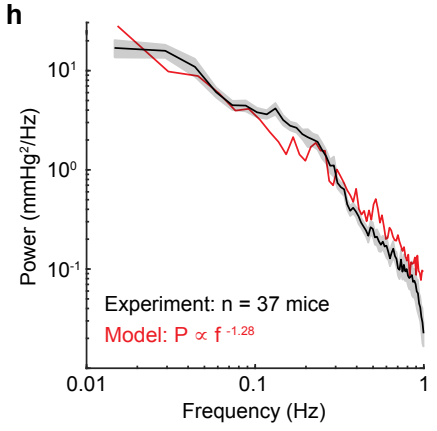

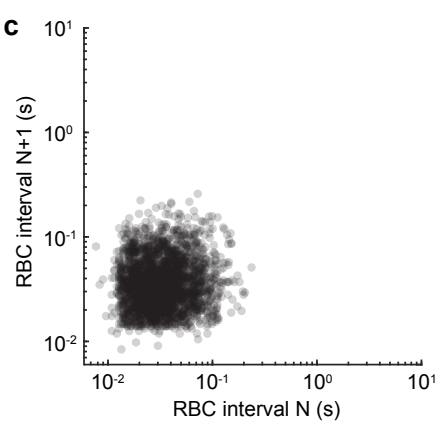
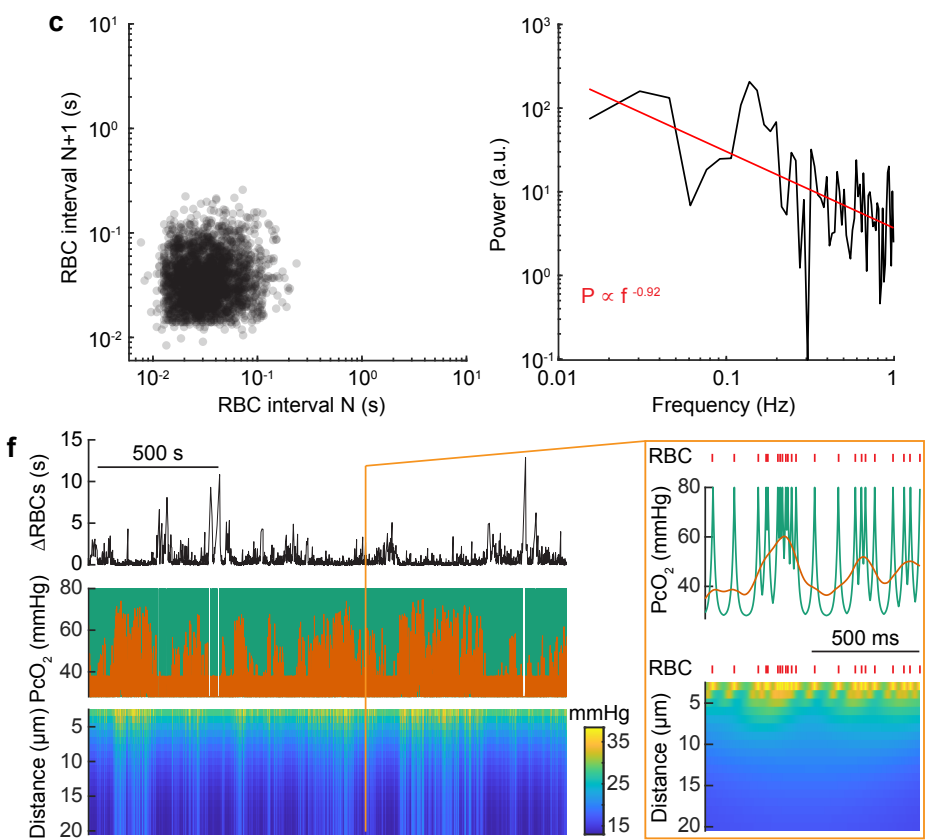
bioRxiv preprint doi: https://doi.org/10.1101/2020.09.18.303164; this version posted September 20, 2020. The copyright holder for this preprint (which was not certified by peer review) is the author/funder. All rights reserved. No reuse allowed without permission.

Fig.S1

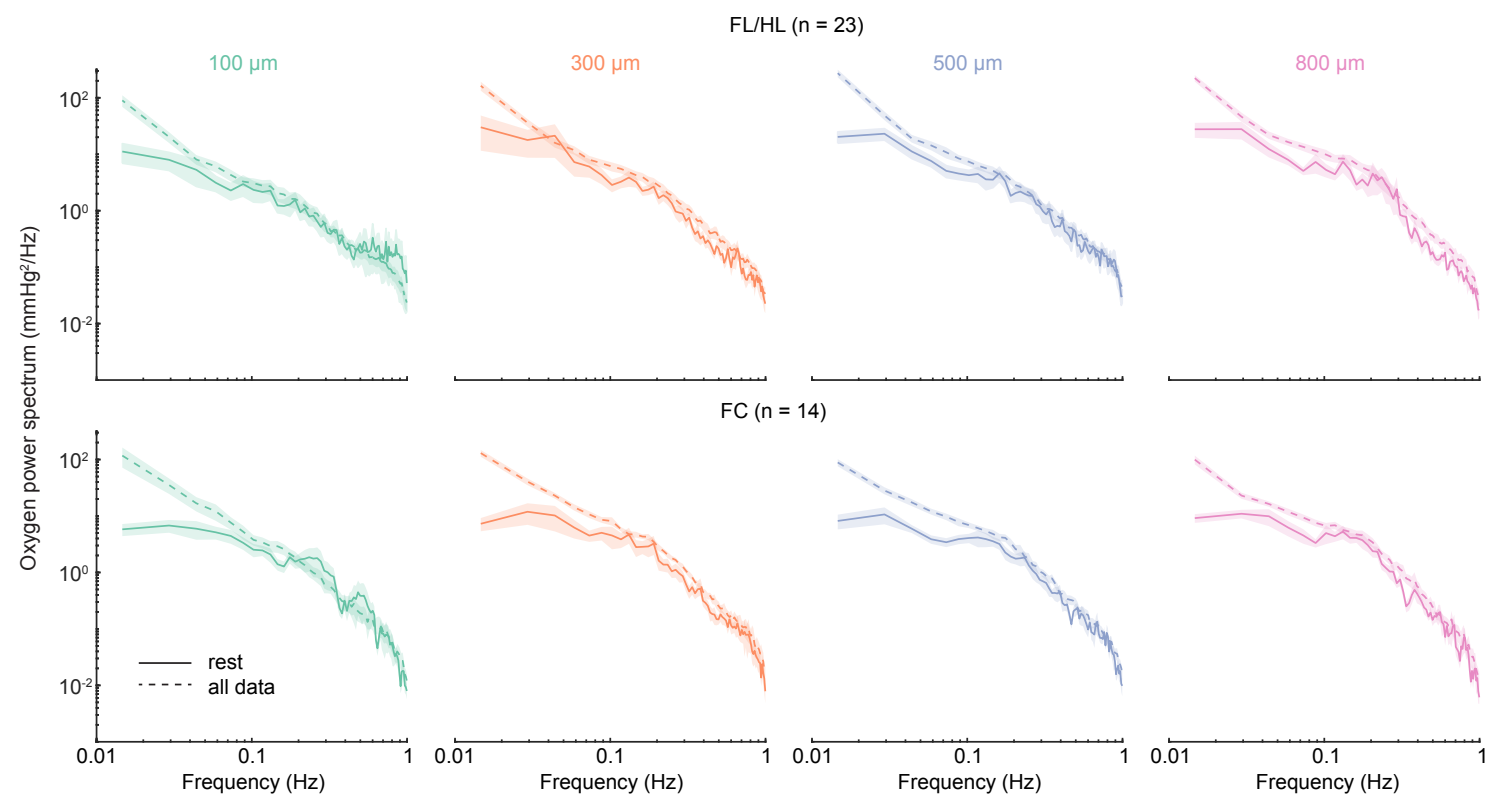


bioRxiv preprint doi: https://doi.org/10.1101/2020.09.18.303164; this version posted September 20, 2020. The copyright holder for this preprint (which was not certified by peer review) is the author/funder. All rights reserved. No reuse allowed without permission.

Fig.S2

a

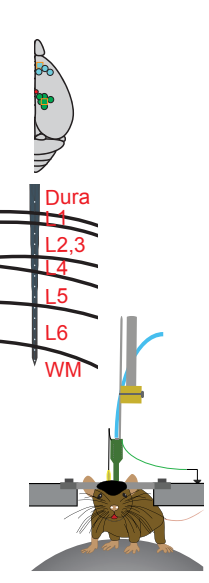

b

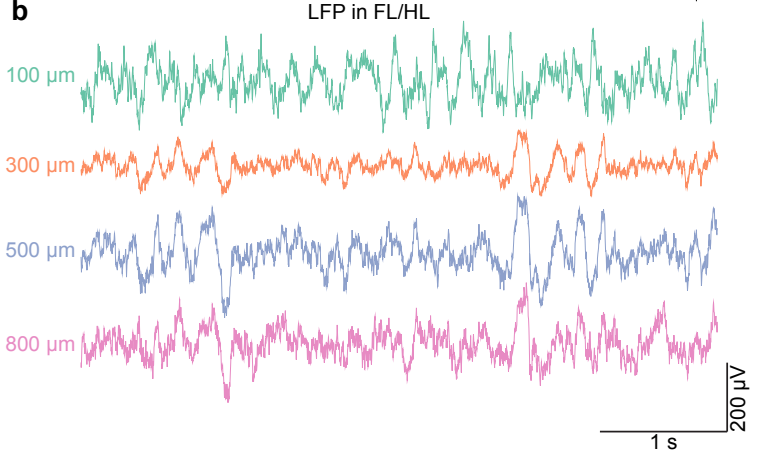

d
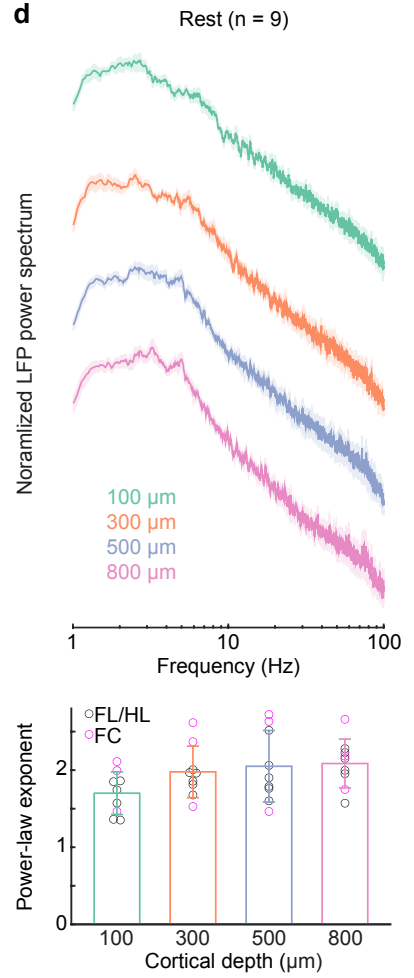

Rest \& locomotion ( $n=9$ )
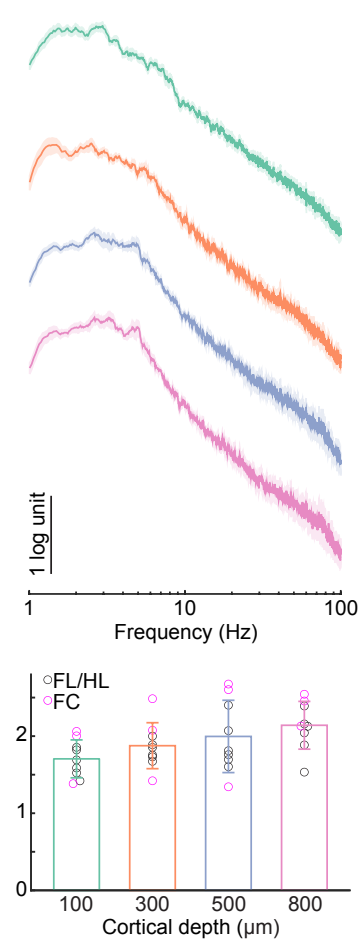

c

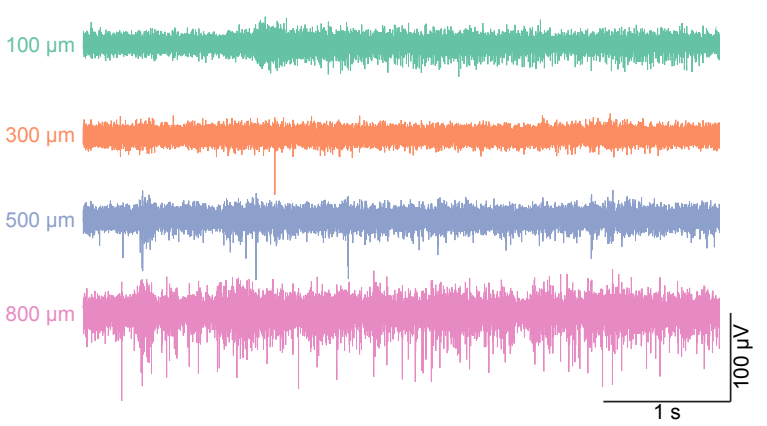

e

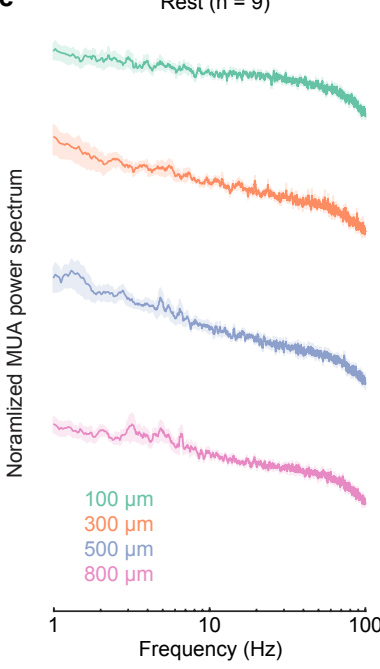

Rest \& locomotion ( $\mathrm{n}=9$ )
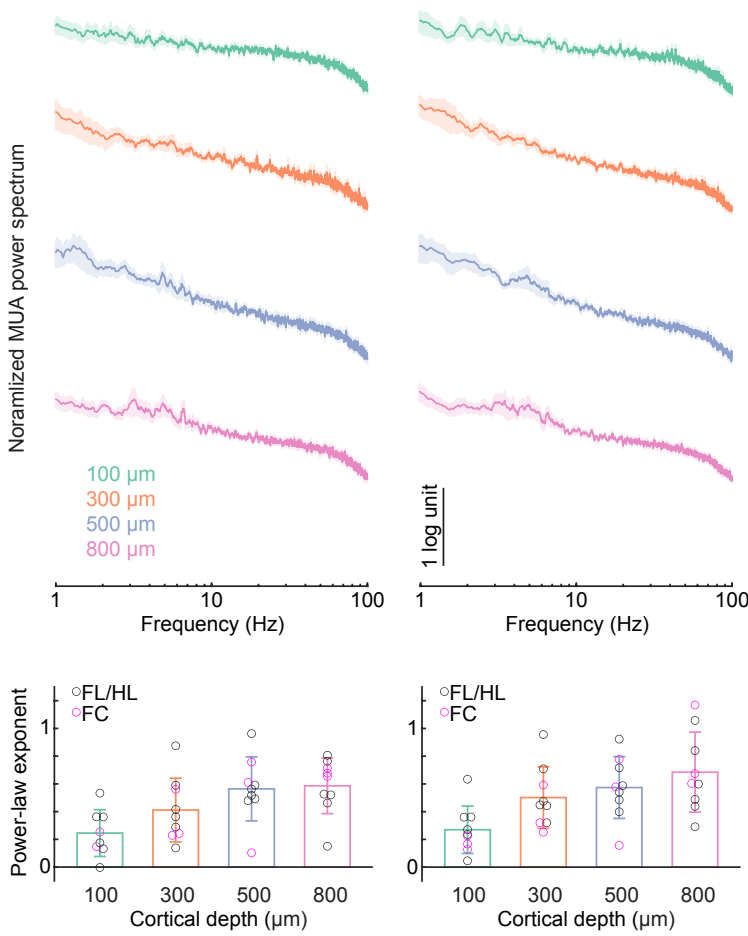
bioRxiv preprint doi: https://doi.org/10.1101/2020.09.18.303164; this version posted September 20, 2020. The copyright holder for this preprint (which was not certified by peer review) is the author/funder. All rights reserved. No reuse allowed without permission.

Fig.S3

a

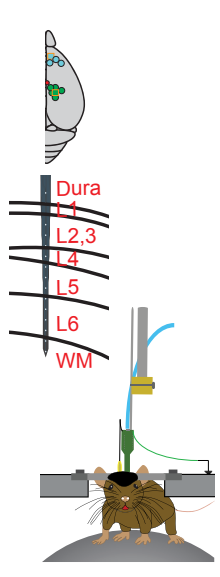

b

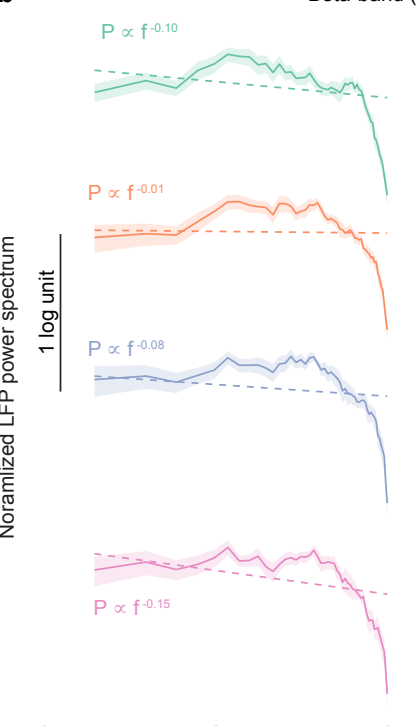

0.01
Beta-band $(10-30 \mathrm{~Hz})$

$$
P \propto f-0.13
$$

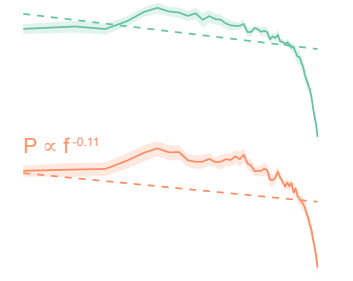

$P \propto f^{-0.22}$
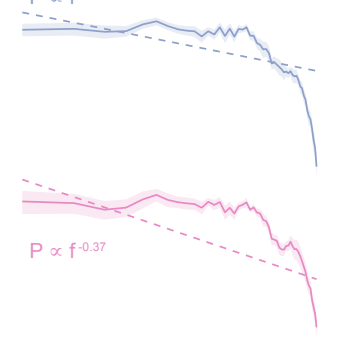

0.1

0.01

c

Frequency $(\mathrm{Hz})$

Frequency $(\mathrm{Hz})$

10.01

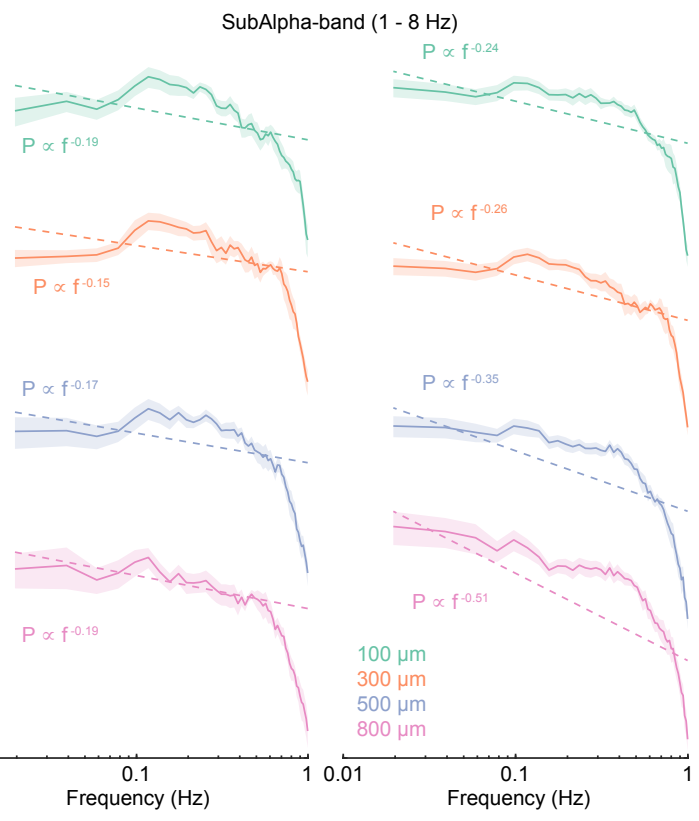


bioRxiv reprint dol: https://doi.org/10.1101/2020.09.18.303164; this version posted September 20, 2020. The copyright holder for this preprint

(which was not certified by peer review) is the author/funder. All rights reserved. No reuse allowed without permission.

Actual oxygen and gamma-band power

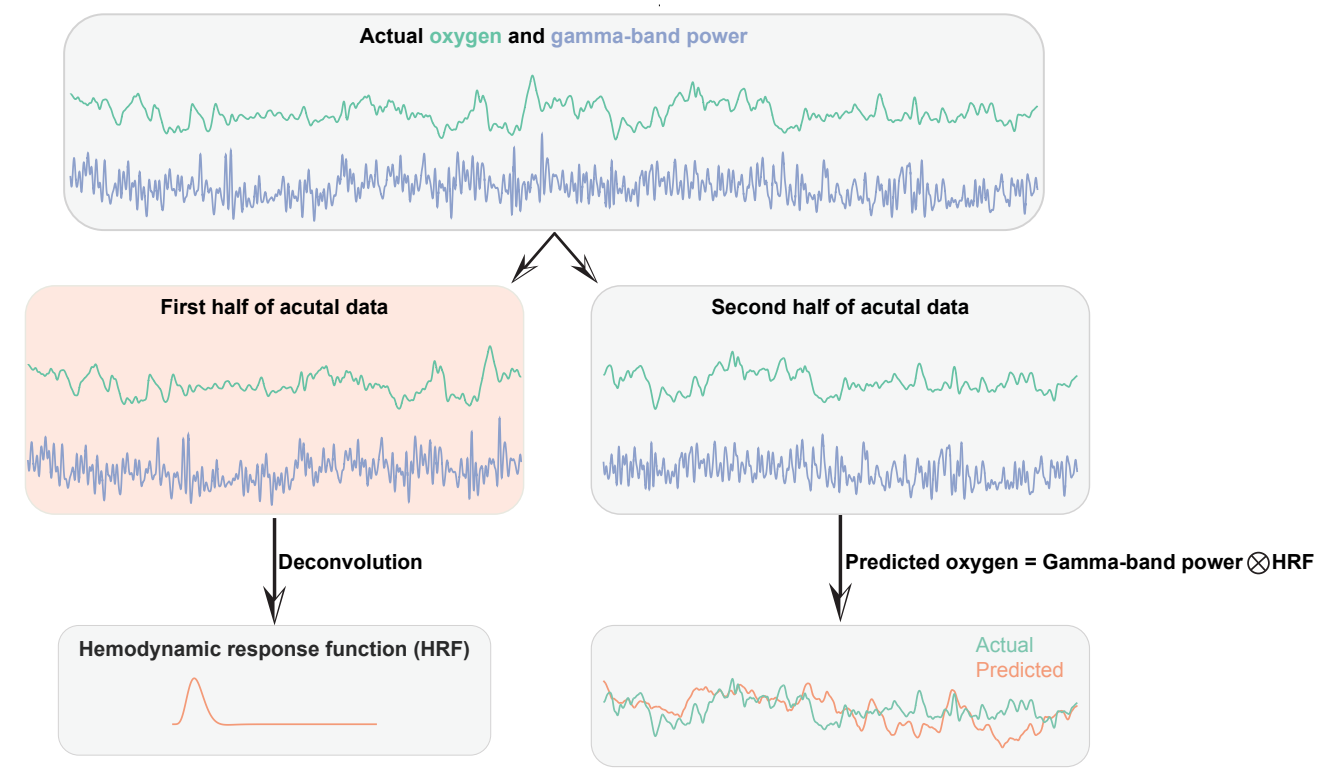


bioRxiv preprint doi: https://doi.org/10.1101/2020.09.18.303164; this version posted September 20, 2020. The copyright holder for this preprint (which was not certified by peer review) is the author/funder. All rights reserved. No reuse allowed without permission.

Fig.S5

a

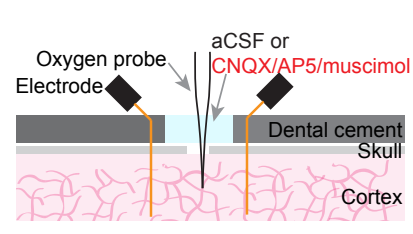

b

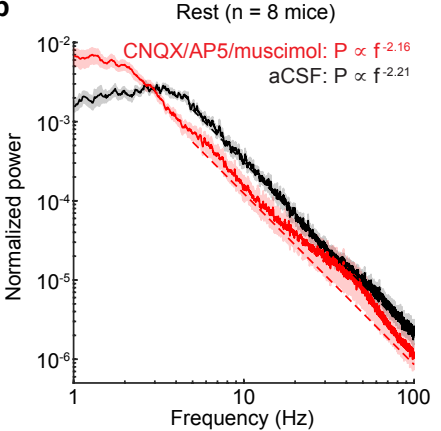

d

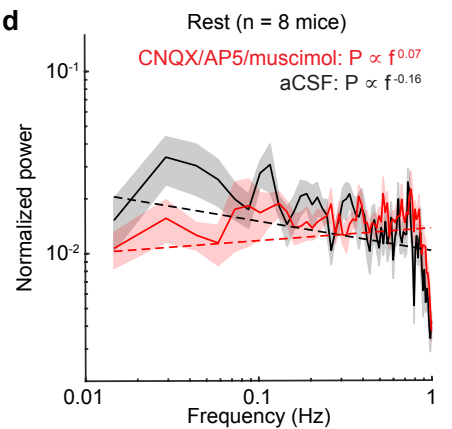

Rest and locomotion ( $\mathrm{n}=9$ mice) 10-2
CNQX/AP5/muscimol: $P \propto f^{-2.08}$
aCSF: $P \propto f^{-1.92}$

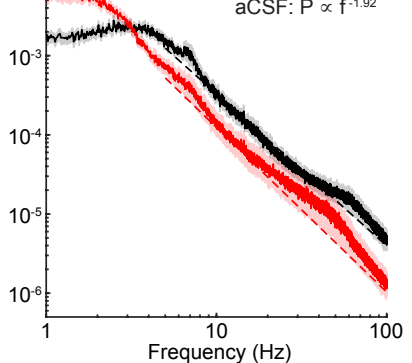

Rest and locomotion $(\mathrm{n}=9$ mice $)$

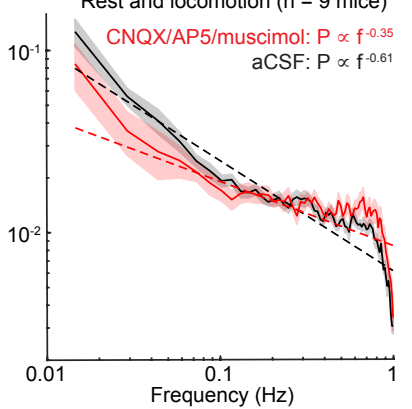

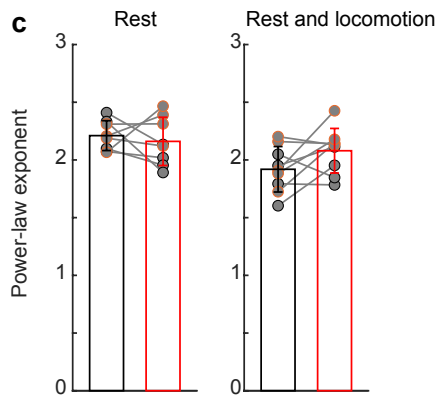

e Rest Rest and locomotion

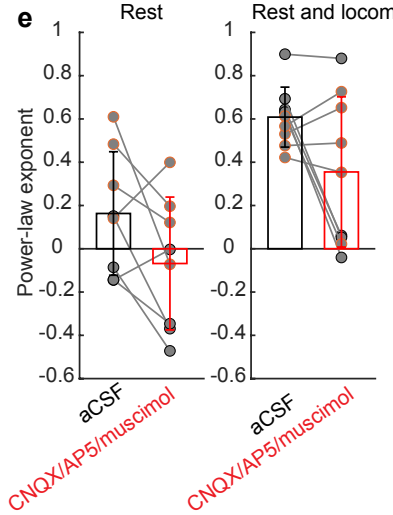


bioRxiv preprint doi: https://doi.org/10.1101/2020.09.18.303164; this version posted September 20, 2020. The copyright holder for this preprint (which was not certified by peer review) is the author/funder. All rights reserved. No reuse allowed without permission.

Fig.S6
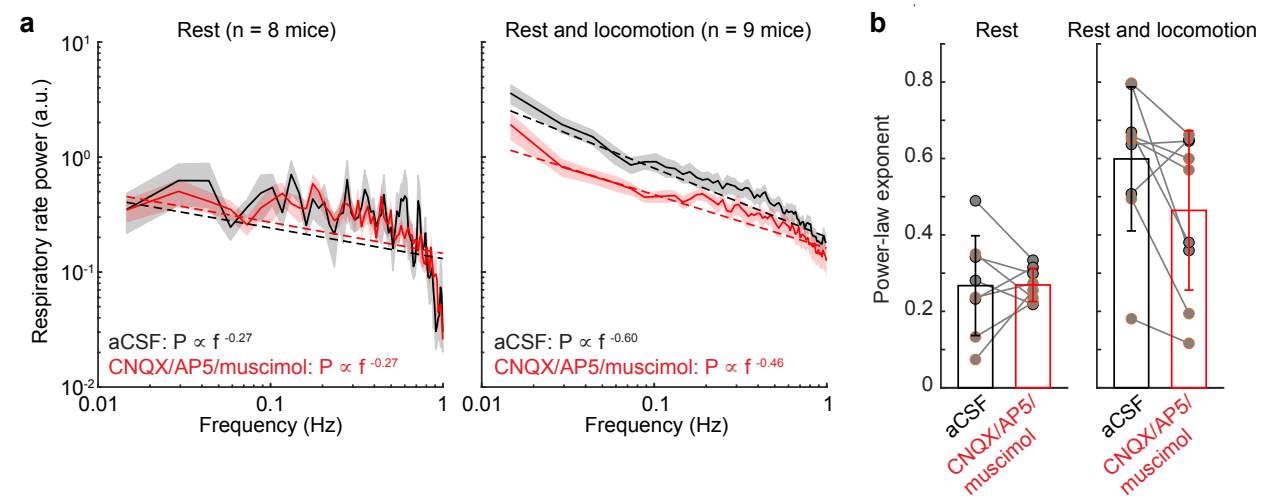
bioRxiv preprint doi: https://doi.org/10.1101/2020.09.18.303164; this version posted September 20, 2020. The copyright holder for this preprint Fig. S7

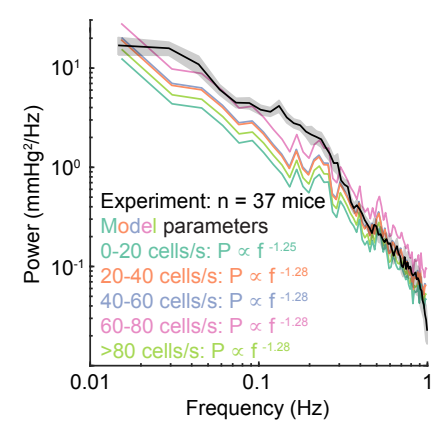

